ARTICLE

\title{
Key activity descriptors of nickel-iron oxygen evolution electrocatalysts in the presence of alkali metal cations
}

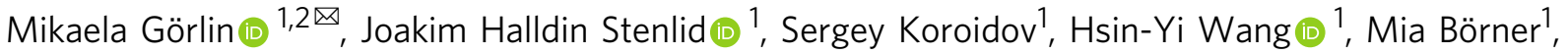

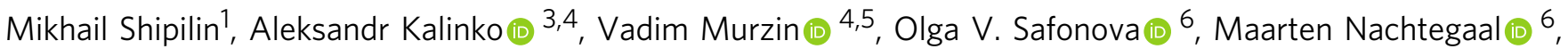 \\ Abdusalam Uheida7, Joydeep Dutta (1] ${ }^{7}$, Matthias Bauer ${ }^{3}$, Anders Nilsson ${ }^{7}$ \& Oscar Diaz-Morales (id 1,8凶
}

Efficient oxygen evolution reaction (OER) electrocatalysts are pivotal for sustainable fuel production, where the Ni-Fe oxyhydroxide $(\mathrm{OOH})$ is among the most active catalysts for alkaline OER. Electrolyte alkali metal cations have been shown to modify the activity and reaction intermediates, however, the exact mechanism is at question due to unexplained deviations from the cation size trend. Our $X$-ray absorption spectroelectrochemical results show that bigger cations shift the $\mathrm{Ni}^{2+/(3+\delta)+}$ redox peak and OER activity to lower potentials (however, with typical discrepancies), following the order $\mathrm{CsOH}>\mathrm{NaOH} \approx \mathrm{KOH}>$ $\mathrm{RbOH}>\mathrm{LiOH}$. Here, we find that the OER activity follows the variations in electrolyte $\mathrm{pH}$ rather than a specific cation, which accounts for differences both in basicity of the alkali hydroxides and other contributing anomalies. Our density functional theory-derived reactivity descriptors confirm that cations impose negligible effect on the Lewis acidity of $\mathrm{Ni}$, $\mathrm{Fe}$, and $\mathrm{O}$ lattice sites, thus strengthening the conclusions of an indirect $\mathrm{pH}$ effect.

\footnotetext{
${ }^{1}$ Department of Physics, AlbaNova University Center, Stockholm University, SE-106 91 Stockholm, Sweden. ${ }^{2}$ Department of Chemistry - Angström laboratory, Uppsala University, Box 538, SE-751 21 Uppsala, Sweden. ${ }^{3}$ Department of Chemistry and Center for Sustainable Systems Design (CSSD), University of Paderborn, Warburger Strasse 100, D-33098 Paderborn, Germany. ${ }^{4}$ Deutsches Elektronen-Synchrotron DESY, Notkestraße 85, D-22607 Hamburg, Germany. ${ }^{5}$ Bergische Universität Wuppertal, Gaußstraße 20, D-42119 Wuppertal, Germany. ${ }^{6}$ Paul Scherrer Institute, CH-5232

Villigen, Switzerland. ${ }^{7}$ Functional Materials, Department of Applied Physics, School of Engineering Sciences, KTH Royal Institute of Technology, Hannes Alfvéns väg 12, SE-114 19 Stockholm, Sweden. ${ }^{8}$ Applied Electrochemistry, School of Chemical Science and Engineering, KTH Royal Institute of Technology,

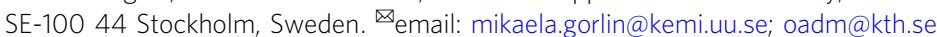


$\mathrm{T}$ o slow down the growth of the steadily increasing carbon footprint, a transition to renewable energy is imperative ${ }^{1}$. Electrochemical water splitting $\left(2 \mathrm{H}_{2} \mathrm{O} \rightarrow 2 \mathrm{H}_{2}+\mathrm{O}_{2}\right)$ offers a zero-carbon route to hydrogen $\left(\mathrm{H}_{2}\right)$ from water ${ }^{2}$, where the main cause of energy loss and cost in this process is the anodic oxygen evolution reaction (OER) ${ }^{3}$. To make water a viable source for $\mathrm{H}_{2}$, efforts therefore need to be focused on more efficient OER electrocatalysts ${ }^{4}$.

Here, we investigate the OER activity and redox-activity using $\mathrm{X}$-ray absorption spectroscopy (XAS) of a $\mathrm{Ni}-\mathrm{Fe}$ oxyhydroxide $(\mathrm{OOH})$ electrocatalyst in the presence of alkali metal cations $\left(\mathrm{Li}^{+}\right.$, $\mathrm{Na}^{+}, \mathrm{K}^{+}, \mathrm{Rb}^{+}, \mathrm{Cs}^{+}$), which is one of the best performing catalysts in alkaline media ${ }^{5,6}$. Electrolyte cations are known to impact the oxygen evolution activity of various oxide-derived electrocatalysts $^{7-12}$, where the activity seemingly follows the trend in cation size, typically increasing from small $\left(\mathrm{Li}^{+}\right)$to large $\left(\mathrm{Cs}^{+}\right)$ cations. However, the role of cations in OER is not entirely understood due to reoccurring discrepancies from the trend in cation size. Moving down the alkali metal group, the cation size increases from $\mathrm{Li}^{+}$to $\mathrm{Cs}^{+}$, along with modifications of several parameters such as decreasing Lewis acidity and electronegativity ${ }^{13}$, increasing molar conductivity ${ }^{14}$ and proton affinity $^{15}$, and increasing basicity of the corresponding alkali hydroxide ${ }^{16}$. Small cations $\left(\mathrm{Li}^{+}\right)$generally form stronger noncovalent interactions with water compared to large cations $\left(\mathrm{Cs}^{+}\right)$, and water becomes more structured around the central cation ${ }^{17}$. Smaller cations are therefore referred to as "structure makers" and bigger cations as "structure breakers". The strong noncovalent interactions between small cations and water disrupt the native H-bonded network and result in large solvation shells ${ }^{17}$, which is usually associated with slower reorientation times and slower kinetics ${ }^{14}$, and observed to alter redox-kinetics of metalcenters ${ }^{18}$. However, there are several unexpected deviations from the cation size trend. Michael et al. ${ }^{19}$. showed that the activity of the $\mathrm{NiOOH}$ catalyst increased from $\mathrm{LiOH}$ to $\mathrm{CsOH}$, whereas the activity of $\mathrm{Ni}(\mathrm{Fe}) \mathrm{OOH}$ was lower in $\mathrm{CsOH}$ compared to both $\mathrm{NaOH}$ and $\mathrm{KOH}$. Zaffran et al. ${ }^{7}$ demonstrated using density functional theory (DFT) that electrolyte cations modify the adsorption energies of OER intermediates $\left({ }^{*} \mathrm{OH},{ }^{*} \mathrm{O},{ }^{*} \mathrm{OOH}\right)$ of the Ni-Fe catalyst, where especially small and strongly acidic cations are not beneficial for OER. Garcia et $a .^{8}$ found using surface ennhanced Raman spectroscopy that large cations promote peroxo-like "active oxygen" species $\left(\mathrm{O}^{-}\right.$or $\left.\mathrm{O}_{2}^{-}\right)$in $\mathrm{NiOOH}$ to a larger extent than small cations, which could explain the higher OER activity in the presence of large cations. Yet, several inconsistencies in the activity trends put the mechanism by which the alkali metal cations modify the OER activity at question.

The catalytic site in the Ni-Fe catalysts has been characterized using in situ XAS, where several studies reveal contradicting information regarding the impact of Fe on the redox-activity of the Ni-site ${ }^{20-27}$. According to several DFT studies, the Fe-site plays a significant role as a low overpotential-site in the bimetallic $\mathrm{Ni}-\mathrm{Fe}$ active site and provides optimal adsorption energies for the OER intermediates ${ }^{28-31}$, which is also supported by experiments ${ }^{32}$. In addition, Fe at coordinatively unsaturated sites such as edge sites or defect sites are predicted as more reactive ${ }^{33-35}$. Recent studies employing in situ soft XAS at the $\mathrm{O} K$-edge also confirmed anionic redox-activity involving the lattice oxygens in the $\mathrm{Ni}-\mathrm{Fe}$ catalyst ${ }^{36,37}$, most likely related to the "active oxygen" earlier identified in Raman spectroscopy ${ }^{38-41}$.

Here, we employ in situ XAS at the $\mathrm{Ni}$ and $\mathrm{Fe} K$-edges to probe the local atomic structure and metal redox-states of an electrodeposited $\mathrm{Ni}_{65} \mathrm{Fe}_{35}(\mathrm{OOH})$ catalyst in the presence of alkali metal cations at alkaline $\mathrm{pH}$ (i.e. $\mathrm{LiOH}, \mathrm{NaOH}, \mathrm{KOH}, \mathrm{RbOH}, \mathrm{CsOH}$ ). We further utilize DFT to explore the correlations between the OER activity and three reactivity properties: The local electron attachment energy $E(\mathbf{r})^{42}$, the local average ionization energy $\bar{I}(\mathbf{r})^{43}$, and the electrostatic potential $V(\mathbf{r})$, to predict how electrolyte cations influence the local Lewis acidity/basicity of the $\mathrm{Ni}-\mathrm{Fe}(\mathrm{OOH})$ lattice sites ${ }^{44-46}$. In short, our data conclude that the modification of alkali metal cations on the OER activity can be explained as a response to a change in the electrolyte $\mathrm{pH}$.

\section{Results}

The impact on the OER activity of the Ni-Fe catalyst by alkali metal cations. A demonstration of the cell setup used for electrochemical and in situ XAS investigations of the electrodeposited $\mathrm{Ni}_{65} \mathrm{Fe}_{35}(\mathrm{OOH})$ catalyst is shown in Fig. 1a, b. The OER activity of the $\mathrm{Ni}_{65} \mathrm{Fe}_{35}$ catalyst was evaluated in $0.1 \mathrm{M}$ alkali hydroxide solutions ( $\mathrm{LiOH}, \mathrm{NaOH}, \mathrm{KOH}, \mathrm{RbOH}, \mathrm{CsOH}$ ), purified according to a modified protocol by Boettcher and co-workers (Supplementary Note 1$)^{47}$. Scanning electron microscopy (SEM) confirmed a platelet-like layered morphology of the $\mathrm{Ni}_{65} \mathrm{Fe}_{35}$ catalyst (Fig. 1c) $)^{47}$. The metal loading was estimated to $\sim 25 \mu \mathrm{g} \mathrm{cm}^{-2}$, corresponding to a film thickness of $\sim 300 \mathrm{~nm}$. Cyclic voltammograms (CVs) and activity trends from steady-state data during the in situ XAS measurements are presented in Fig. 1d, e. (The spectra will be presented in the XAS section below.) We find that the activity increases in the order of $\mathrm{LiOH}<\mathrm{RbOH}<\mathrm{KOH}<$ $\mathrm{NaOH}<\mathrm{CsOH}$, thus does not exactly follow the overall size of the cations (see Fig. 1e). A larger data set recorded "in house" largely confirms the activity trend from the XAS data set, where the OER overpotential $\left(\eta_{\text {OER }}\right)$ at $10 \mathrm{~mA} \mathrm{~cm}^{-2}$ increases in the order of $\mathrm{CsOH} \quad(295 \mathrm{mV})<\mathrm{NaOH} \quad(309 \mathrm{mV})<\mathrm{KOH} \quad(316 \mathrm{mV})<\mathrm{RbOH}$ $(331 \mathrm{mV})<\mathrm{LiOH}(352 \mathrm{mV})$, see Fig. $2 \mathrm{a}^{6}$.

Since the two data sets (XAS vs. "in house") were measured using two different reference electrodes $(\mathrm{Ag} / \mathrm{AgCl}$ vs. $\mathrm{RHE})$, the trends are validated in Supplementary Fig. 1. The Tafel slopes are in line with the overall activity trends, decreasing from $41 \mathrm{mV} \mathrm{dec}^{-1}$ in $\mathrm{LiOH}$ to $38 \mathrm{mV} \mathrm{dec}{ }^{-1}$ in $\mathrm{CsOH}$, and with the typical discrepencies in between the two extremes (see Fig. 2b and Supplementary Fig. 1f). The turnover frequency was estimated based on the total metal loading $\left(\mathrm{TOF}_{\text {mass }}\right)$ including both the amount of $\mathrm{Ni}$ and Fe determined by elemental analysis (ICP-OES), see the Methods section for more details. The $\mathrm{TOF}_{\text {mass }}$ is in good accord with the geometric activity trend, and increases in the order of $\mathrm{LiOH}\left(0.009 \mathrm{~s}^{-1}\right), \mathrm{RbOH}\left(0.014 \mathrm{~s}^{-1}\right), \mathrm{KOH}\left(0.015 \mathrm{~s}^{-1}\right), \mathrm{NaOH}$ $\left(0.016 \mathrm{~s}^{-1}\right)$, and $\mathrm{CsOH}\left(0.023 \mathrm{~s}^{-1}\right)$ at $1.56 \mathrm{~V}$ in purified $0.1 \mathrm{M}$ alkali hydroxides (more data is shown in Supplementary Fig. 1 and activity parameters in Supplementary Table 1). The $\mathrm{TOF}_{\text {mass }}$ appears fairly low at first glance, however, agrees well with reports of other Ni-Fe catalysts at similar conditions ${ }^{6}$, where the turnover frequency is generally lower for thicker films and in lower electrolyte concentrations, as we also show below ${ }^{48,49}$. Although the cation trends herein agree with the reported trends for $\mathrm{Ni}-\mathrm{Fe}$ catalysts, there are several discrepancies between these studies $7,8,19,40$. As mentioned Michael et al. ${ }^{19}$ found highest activity of their $\mathrm{NiOOH}$ catalyst in $\mathrm{CsOH}$ in $\mathrm{Fe}$-free conditions, however, when Fe-impurities were added to the electrolyte, the activity in $\mathrm{CsOH}$ decreased drastically. On the contrary to most of these studies, Ding et al. ${ }^{9}$ found that the activity was highest in $\mathrm{LiOH}$ for a series of transition metal oxides (Co, Fe, Mn), which was regarded to a suppression of the activity for the oxygen reduction reaction (ORR), which is the "backward" reaction for OER. Suntivich et al. ${ }^{50}$ also found a generally lower ORR activity in $\mathrm{LiOH}$, however, the OER activity was still lowest in $\mathrm{LiOH}$ in line with other studies.

The activity drop observed in $\mathrm{RbOH}$ we cannot find support for due to the lack of reports for $\mathrm{Ni}-\mathrm{Fe}$ catalysts. On the contrary, a higher than expected activity was found in $\mathrm{RbOH}$ on $\mathrm{Pt}(111)$ in a study by Tymoczko et al. ${ }^{11}$, although the explanation for this 
a

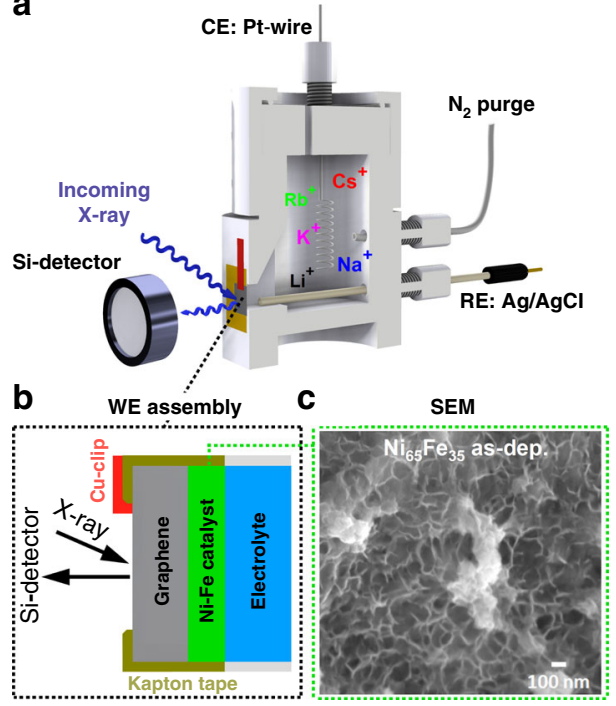

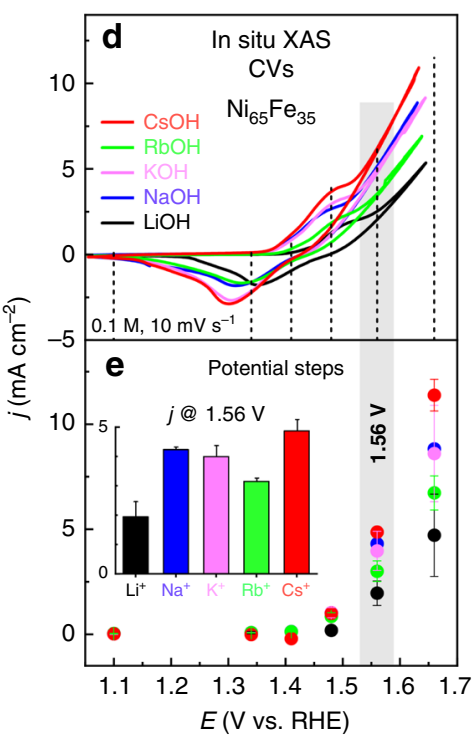

Fig. 1 Electrochemical cell setup and OER activity during in situ XAS. a Schematic drawing of the cell used for the in situ XAS investigations of the $\mathrm{Ni}_{65} \mathrm{Fe}_{35}(\mathrm{OOH})$ catalyst, carried out in purified $0.1 \mathrm{M} \mathrm{LiOH}, \mathrm{NaOH}, \mathrm{KOH}, \mathrm{RbOH}$, and $\mathrm{CsOH}$. The cell body was made of PTFE/PEEK $(\varnothing=50 \mathrm{~mm}$, with a $6 \times$ $6 \mathrm{~mm}$ X-ray transparent window), a leak-free $\mathrm{Ag} / \mathrm{AgCl}$ reference electrode, and a Pt-mesh as counter electrode. $\mathbf{b}$ Enlargement of the working electrode showing the $\sim 300 \mathrm{~nm}$ thick $\mathrm{Ni}_{65} \mathrm{Fe}_{35}$ film electrodeposited on a $\sim 35 \mu \mathrm{m}$ thick graphene-sheet as working electrode. c SEM image of the as-deposited $\mathrm{Ni}_{65} \mathrm{Fe}_{35}$ film on the graphene electrode. d CVs at $10 \mathrm{mV} \mathrm{s}^{-1}$ during the in situ XAS measurements at the P64 beamline at Petra III (DESY). e Potential steps during collection of the $\mathrm{Ni}$ and $\mathrm{Fe} \mathrm{K}$-edges, where the inset shows a trend plot of current density $(j)$ at $1.56 \mathrm{~V}$ against the electrolyte cation. All potentials have been converted from the $\mathrm{Ag} / \mathrm{AgCl}$ to the RHE potential scale. Error bars represent the standard error from the overall number of measurements.

remained ambiguous. Here we observe that electrolyte cations have a clear effect on the potential of the nickel redox peak, located around $1.5 / 1.3 \mathrm{~V}$ vs. RHE in the CVs (Fig. 2c). This is assigned to the reversible oxidation/reduction of $\mathrm{Ni}^{2+} \leftrightarrow \mathrm{Ni}^{3+/ 4+}$ (which we denote " $\mathrm{Ni}^{2+/(3+\delta)+" ~ s i n c e ~ t h e ~ f r a c t i o n ~ o f ~} \mathrm{Ni}^{3+/ 4+}$ depends on the potential) via deprotonation of lattice hydroxide $(-\mathrm{OH})$ to oxidic groups $(-\mathrm{O})^{38}$. The anodic redox peak $\left(E_{\mathrm{p}, \mathrm{a}}\right)$ shifts to higher potentials by $\sim 40 \mathrm{mV}$ from $\mathrm{CsOH}$ to $\mathrm{LiOH}$, which agrees with the shift of the OER activity in the same direction (see Supplementary Fig. 1g-i). The integrated anodic peak charge $\left(Q_{\mathrm{p}, \mathrm{a}}\right)$ is only $\sim 0.5 \mathrm{e}^{-}$per $\mathrm{Ni}$, whereas the cathodic peak charge $\left(Q_{\mathrm{p}, \mathrm{c}}\right)$ is closer to $\sim 1 \mathrm{e}^{-}$per Ni since it is well-separated from the catalytic current (see Fig. $2 c$ and Supplementary Fig. $1 g-i)^{51}$. A similar cation effect has been recognized by Yang et al. ${ }^{40}$ where the tetrabutylammonium $\left(\mathrm{TBA}^{+}\right)$and tetramethylammonium $\left(\mathrm{TMA}^{+}\right)$cations (thought to interact with "active oxygen") shifted the redox peak similarly by $\sim 78 \mathrm{mV}$ to higher potentials. Such modifications were also recognized by Strmcnik et al. ${ }^{10}$ for metallic $\mathrm{Pt}$, where strongly adsorbing $\mathrm{Li}^{+}$ions were proposed to form clusters with surface adsorbed ${ }^{*} \mathrm{OH}$ species, and thereby blocking the active sites. Suntivich et al. ${ }^{50}$ instead proposed that $\mathrm{Li}^{+}$ions interfere with the rate-limiting steps/species in the catalytic cycle via strong non-covalent interactions, and thereby impact the reaction energy and the kinetics. This is in line with the DFT study by Zaffran et al. ${ }^{7}$, where electrolyte cations (alkali and alkali earth) were found to influence the adsorption energies of the OER intermediates.

Catalyst-cation interactions and electrolyte impurities. SEM analysis post-OER did not indicate any significant change in the morphology of the $\mathrm{Ni}-\mathrm{Fe}$ catalyst (Supplementary Fig. 2). Energy-dispersive X-ray spectroscopy (EDS) further supports a non-covalent catalyst-cation interaction, since there were no traces of cations in the $\mathrm{Ni}-\mathrm{Fe}$ films post-OER after carefully rinsing with MilliQ-water (Supplementary Fig. 3a, b). Only in films not rinsed as carefully, traces of alkali cations were occasionally detected, which is more likely traces of dried hydroxide salts. The $\mathrm{Ni}-\mathrm{Fe}$ catalyst films on the other hand were found to exhibit a significant local inhomogeneity in the Ni:Fe composition, where several local areas have a clear Fe-enrichment (Supplementary Fig. 3c, d and Supplementary Table 2). Such local compositional inhomogeneity has earlier been reported beyond $\sim 25 \% \mathrm{Fe}$-content for $\mathrm{Ni}-\mathrm{Fe}$ catalysts $^{20,52}$. Since these variations were also present in the as-deposited $\mathrm{Ni}-\mathrm{Fe}$ films, it at least excludes that this is related to a specific alkali cation. Furthermore, electrolyte impurities (such as $\mathrm{Fe}$ ) might incorporate to surface sites and thereby affect the catalytic activity and redoxpeak system of Ni-based catalysts, whereby we used ICP-OES (and EDS) to scan the alkali hydroxides. Impurities were found only in the as-received electrolytes; $\sim 5 \mathrm{ppm}$ Fe and $\sim 3 \mathrm{ppm} \mathrm{Zn}$ in $\mathrm{RbOH}$, and $\leq 1 \mathrm{ppm} \mathrm{Fe}$ in $\mathrm{CsOH}$ (Supplementary Fig. 4a), whereas no impurities were found above the detction limit in the purified hydroxides, suggesting that the purification step was successful (Supplementary Fig. 4b, c).

In situ XAS in presence of alkali metal cations. In situ XAS was acquired at the $\mathrm{Ni}$ and $\mathrm{Fe} K$-edges in purified $0.1 \mathrm{M}$ alkali hydroxides at the P64 beamline at Petra III (DESY, Hamburg). The Ni or Fe K-edge XAS probes dipole-allowed transitions from the $1 \mathrm{~s}$ core level to unoccupied $4 \mathrm{p}$ valence states of the $3 \mathrm{~d}$ metals, and the pre-edge feature $\sim 10 \mathrm{eV}$ below the edge is assigned to quadrupole transitions to empty $3 \mathrm{~d}$ states $^{53}$. In Fig. $3 \mathrm{a}, \mathrm{b}$, the Xray absorption near edge spectra (XANES) of the $\sim 300 \mathrm{~nm}$ thick $\mathrm{Ni}_{65} \mathrm{Fe}_{35}$ catalyst film are shown in the non-catalytic "ground" state $(1.1 \mathrm{~V})$, and at a selected potential in the half-oxidized state after the redox-onset $(1.48 \mathrm{~V})$ where the differences between the metal cations were largest (see also Supplementary Figs. 5-8). At non-catalytic potential, and prior to the onset of metal oxidation (i.e., between $1.1 \mathrm{~V}-1.34 \mathrm{~V}$ vs. RHE), the $K$-edge positions match low-valent $\mathrm{Ni}^{2+} \mathrm{Fe}^{3+}$, independent of the electrolyte cation 

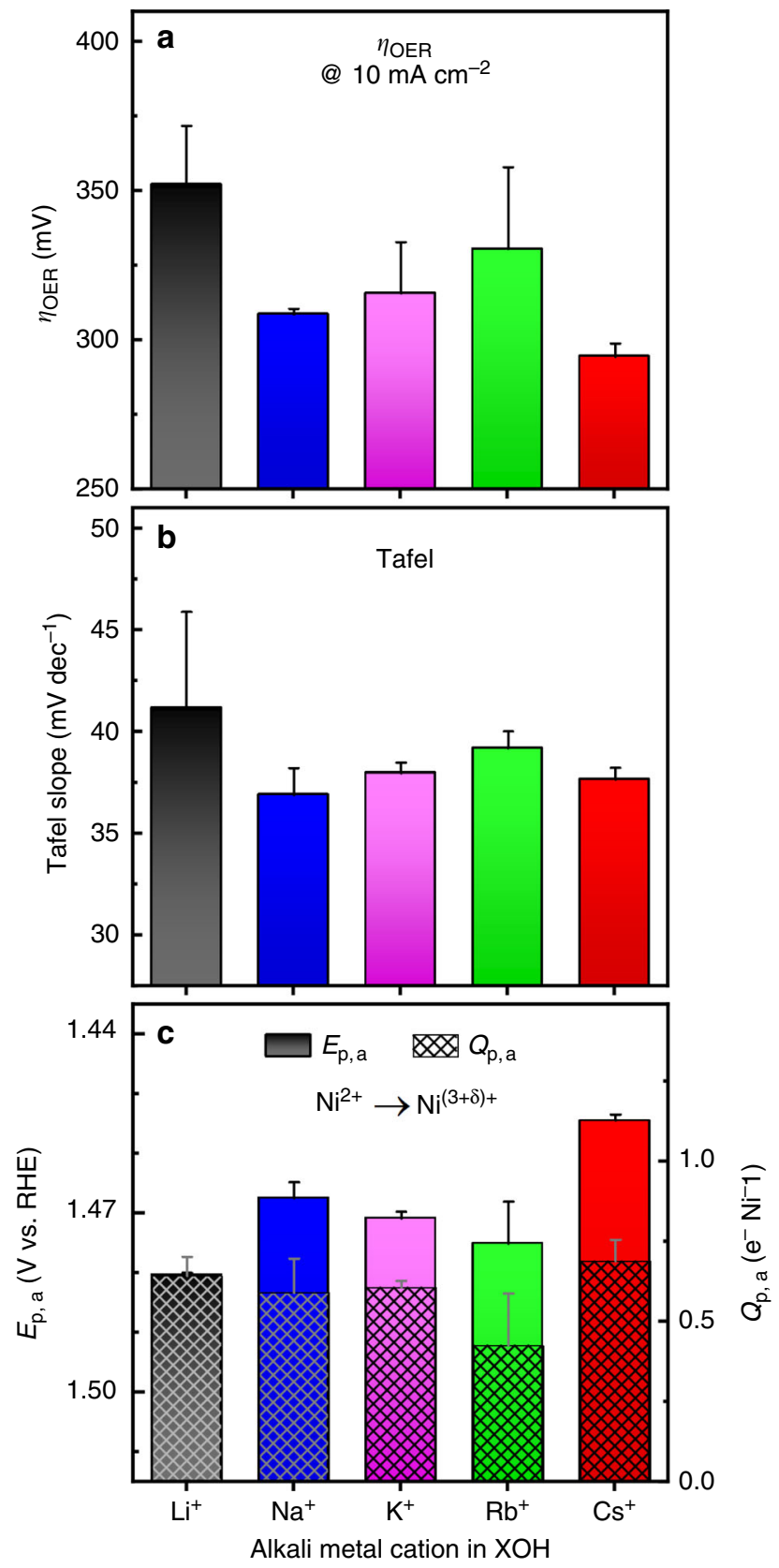

Fig. 2 OER activity trends at the influence of alkali metal cations. The OER activity of the $\mathrm{Ni}_{65} \mathrm{Fe}_{35}$ catalyst in purified $0.1 \mathrm{M} \mathrm{XOH}$ electrolytes $\left(\mathrm{X}=\mathrm{Li}^{+}\right.$, $\mathrm{Na}^{+}, \mathrm{K}^{+}, \mathrm{Rb}^{+}$, and $\mathrm{Cs}^{+}$) measured "in house". a OER overpotential ( $\left.\eta_{\mathrm{OER}}\right)$ at $10 \mathrm{~mA} \mathrm{~cm}^{-2}$ from steady-state conditions. b Tafel slope analysis extracted from steady-state conditions. $\mathbf{c}$ The anodic peak positions $\left(E_{\mathrm{p}, \mathrm{a}}\right)$ of the $\mathrm{Ni}^{2+} \rightarrow$ $\mathrm{Ni}{ }^{(3+\delta)}+$ redox peak (left), and the corresponding integrated anodic peak charge $\left(Q_{p, a}\right.$, right) obtained from $C V s$ at $10 \mathrm{mV} \mathrm{s}^{-1}$. All data in this figure was recorded using a reversible hydrogen electrode (RHE) as a reference electrode. Error bars show the standard error from the overall number of measurements.

(see Fig. 3e; Supplementary Fig. 9a, b and Supplementary Table 3). Simulations of the $k^{3}$-weighted extended X-ray absorption fine structure (EXAFS) using scattering functions generated in FEFF $^{54}$ show that $\mathrm{Ni}-\mathrm{O}$ is coordinated at a distance of $\sim 2.04 \AA$, Ni-Ni at $\sim 3.06 \AA, \mathrm{Fe}-\mathrm{O}$ at $\sim 1.99 \AA$, and $\mathrm{Fe}-\mathrm{Ni}$ at $\sim 3.06 \AA$, which match the oxidation states from the edge positions, consistent with a $\mathrm{Ni}^{2+} \mathrm{Fe}^{3+}$ ground state (see Fig. 3c, d; Supplementary Fig. 9c, d; Supplementary Tables 4 and 5). Hence, no distinct differences are observed for different electrolyte

cations in the non-catalytic state. Above the oxidation threshold (above $\sim 1.35 \mathrm{~V}$ ), the $\mathrm{Ni} K$-edge starts to shift to higher energies, consistent with an increase in the metal oxidation state from $\mathrm{Ni}^{2+}$

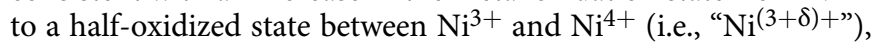
however, the absolute edge shift depends on the electrolyte cation (see OX region in Fig. 3e). At $1.48 \mathrm{~V}$, the differences between the cations are largest, and the $\mathrm{Ni} K$-edge positions increase in the order $\mathrm{LiOH}<\mathrm{RbOH}<\mathrm{KOH} \approx \mathrm{CsOH}<\mathrm{NaOH}$ (Supplementary Fig. 10a-c). This is similar to the characteristic trend seen in the electrochemical characterization, except that $\mathrm{NaOH}$ has a larger than expected edge shift, which we will come back to later. Conversely, the Fe $K$-edge does not shift at the main edge, and all Fe-sites therefore appear to remain as $\mathrm{Fe}^{3+}$ independent of the potential and electrolyte cation. Although, there is a small increase in the pre-edge intensity and a positive shift of the whiteline centroid as observed in previous studies (Supplementary Fig. 6$)^{20,21,23,25}$. At higher potentials with a stronger catalytic rate $(1.66 \mathrm{~V})$, the $\mathrm{Ni} K$-edge is consistent with an overall oxidation state of $\mathrm{Ni}^{3.8+}$, meaning that all sites have oxidized to $\mathrm{Ni}^{3+}$, and further $\sim 80 \%$ of these to $\mathrm{Ni}^{4+}$, where the differences between the cations are again smaller (Fig. 3e and Supplementary Table 3). This is in large agreement with previous work ${ }^{20}$, however, the oxidation states of both sites ( $\mathrm{Ni}$ and $\mathrm{Fe})$ are disputed and varies across studies ${ }^{21-23,25,48}$. The simulations of the $k^{3}$-weighted EXAFS confirms a shortening of both the $\mathrm{Ni}-\mathrm{O}$ and $\mathrm{Fe}-\mathrm{O}$ bonds at oxidative potential, and at $1.66 \mathrm{~V}$ the following average bond lengths are obtained; $\mathrm{Ni}-\mathrm{O}(\sim 1.88 \AA), \mathrm{Ni}-\mathrm{Fe}(\sim 2.82 \AA), \mathrm{Fe}-\mathrm{O}$ $(\sim 1.94 \AA)$, and $\mathrm{Fe}-\mathrm{Ni}(\sim 2.89 \AA)$, although, the absolute bond lengths depend on the electrolyte cation (Fig. $3 \mathrm{f}$ and Supplementary Tables 4 and 5). The Ni-O distances are consistent with an oxidation state of $\mathrm{Ni}^{3.7+}$, thus largely agree with the $\mathrm{Ni} K$-edge positions (Supplementary Figs. 9c and 10). The short $\mathrm{Fe}-\mathrm{O}$ bond on the other hand contradicts the Fe $K$-edge position, and is consistent with $\sim 60-90 \%$ of the Fe-centers being oxidized to $\mathrm{Fe}^{4+}$ at $1.66 \mathrm{~V}$, depending on the cation (Supplementary Figs. 9d and 10 and Supplementary Table 5). Michael et al. ${ }^{19}$ also observed in Raman spectroscopy that $\mathrm{CsOH}$ promotes a longer $\mathrm{Ni}-\mathrm{O}$ bond in the $\mathrm{Ni}(\mathrm{Fe}) \mathrm{OOH}$ catalyst compared to $\mathrm{LiOH}$. Our XAS data herein instead supports a shorter $\mathrm{Ni}-\mathrm{O}$ bond, which just reflects the relatively higher oxidation state of $\mathrm{Ni}$ in $\mathrm{CsOH}$. Although there are some differences between the cations, the correlation between the $\mathrm{Fe}-\mathrm{O}$ bond length, electrolyte cation, and OER activity is not particularly strong. This does not necessarily rule out $\mathrm{Fe}$ as the active site, but might suggest that the Fe-site is not rate-limiting for the turnover rate in contrast to the Ni-site. The changes related to the Fe XAS spectra are in fact a matter of controversy. Dau and co-workers did not regard the spectral change to an increase in the Fe oxidation state due to the lack of an edge shift, but instead proposed geometric distortions ${ }^{21,23}$. Although, herein we observe a strong contraction of the Fe-O bond, which is usually associated with an increase in the oxidation state. Other spectroscopic techniques also support a fraction (3-21\%) of high-valent Fe-species ( +4 and beyond) being formed during $\mathrm{OER}^{26,55}$. Another possible explanation, as mentioned by Hunter et al. ${ }^{56}$, is a spin-state transition from highspin $\mathrm{Fe}^{3+}$ to low-spin $\mathrm{Fe}^{3+57}$, which could result in a similar spectral change as both geometry and charge-transfer effects, the latter proposed for $\mathrm{Ni}-\mathrm{Fe}$ catalysts ${ }^{25}$. This will have to be addressed in future studies.

Noteworthy, the differences between the cations are most pronounced at quasi-equilibrium conditions (in the OX region in Fig. 3e) and diminish at higher potentials (in the OER region). This suggests that the electrolyte cations do not significantly alter the equilibrium levels of oxidized $\mathrm{Ni}^{(3+\delta)+}$, but rather shifts the onset potential of oxidation. Repetitions and a cross-check with another data set from a different beamline (SuperXAS-XD10 at 
a
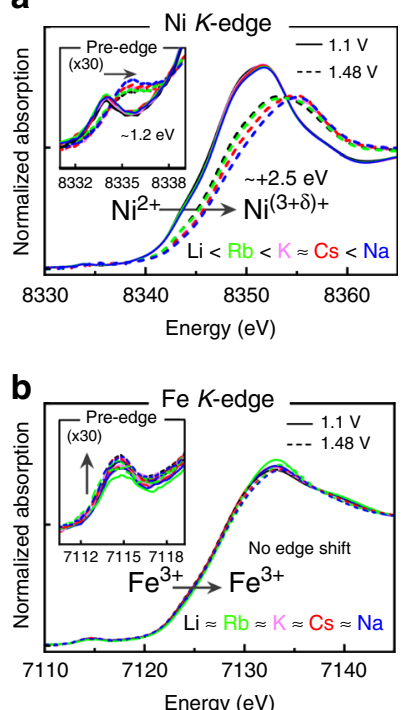

c

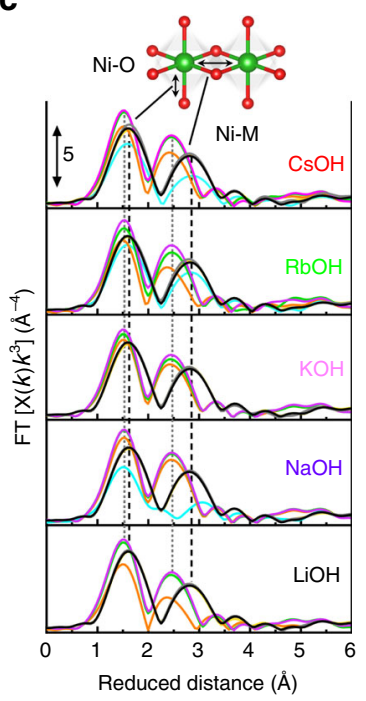

d

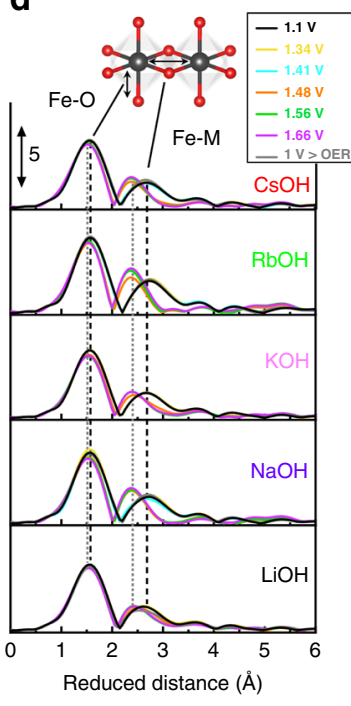

e
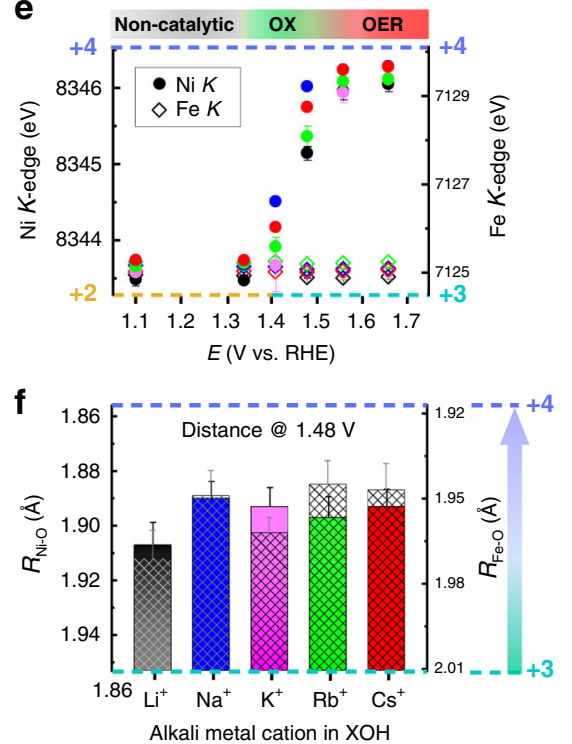

Fig. 3 In situ X-ray absorption spectroscopy in presence of alkali metal cations. In situ XAS was performed at the Ni and Fe $K$-edges of the $\mathrm{Ni}_{65} \mathrm{Fe}_{35}(\mathrm{OOH})$ catalyst in purified $0.1 \mathrm{M} \mathrm{XOH}$ electrolytes $\left(\mathrm{X}=\mathrm{Li}^{+}, \mathrm{Na}^{+}, \mathrm{K}^{+}, \mathrm{Rb}^{+}, \mathrm{Cs}^{+}\right.$). a Ni XANES at $1.1 \mathrm{~V}$ (solid curves) and at $1.48 \mathrm{~V}$ (dashed curves). The inset shows an enlargement of the pre-edge region and the arrow indicates the direction of change upon oxidizing potential. $\mathbf{b}$ Fe $\mathrm{XANES}$ at $1.1 \mathrm{~V}$ (solid curves) and at $1.48 \mathrm{~V}$ (dashed curves). The inset shows an enlargement of the pre-edge region with the direction of change indicated by the arrow. $\mathbf{c}$ The $k^{3}$-weighted FT-EXAFS at the Ni K-edges. d The $k^{3}$-weighted FT-EXAFS at the Fe $K$-edges. e Ni and Fe $K$-edge positions vs. the applied potential. The

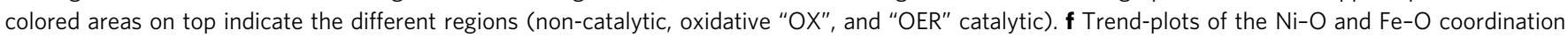

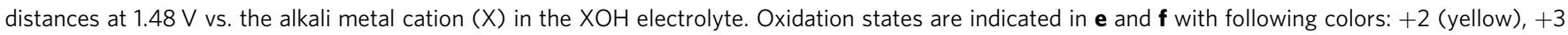
(green), and +4 (purple). Error bars show the standard error from the overall number of measurements.

SLS, PSI) confirms that the cation-induced differences in the $\mathrm{Ni}$ $K$-edge positions are relatively small, and in fact close to the overall standard error (Supplementary Fig. 11). Overall, the second data set supports that the fraction of oxidized $\mathrm{Ni}^{(3+\delta)+}$ increases from small to large cations, where the lowest and highest oxidation states are found in $\mathrm{LiOH}$ and $\mathrm{CsOH}$, respectively. However, we find that the absolute edge positions are influenced by the catalyst film thickness which is related to a shift in the OER overpotential with loading, which might therefore introduce further discrepancies in the edge positions between the cations. More information on the XAS data analysis is provided in Supplementary Note 2, and EXAFS simulations and calibration curves are shown in Supplementary Figs. 12-14.

The electrolyte $\mathrm{pH}$ as an OER activity descriptor. To address a possible $\mathrm{pH}$-effect imposed by the alkali cations, we extended our investigations to a wider range of molar concentrations, namely $0.05 \mathrm{M}, 0.1 \mathrm{M}, 0.25 \mathrm{M}, 0.5 \mathrm{M}$, and $1 \mathrm{M}$ alkali hydroxides. A reversible hydrogen electrode (RHE) was employed as a reference electrode for these measurements to avoid unknown shifts in the potential-scale due to small variations in the $\mathrm{pH}^{58}$. Our results show that the $\mathrm{Ni}_{65} \mathrm{Fe}_{35}$ catalyst responds to an increased electrolyte concentration (and thus $\mathrm{pH}$ ) with a shift of both the $\mathrm{Ni}^{2+/(3+\delta)+}$ redox peak and the OER activity to lower potentials; this effect is remarkably similar to the effect seen from small to large cations (see Fig. 4a, b and Supplementary Fig. 15a). Both the peak positions $\left(E_{\mathrm{p}, \mathrm{a}}\right)$ and the activity are found to shift in the same direction and with fairly similar magnitudes $(\sim 40-50 \mathrm{mV})$, and therefore the separation between these two processes on a potential-scale remains fairly constant $(\sim 70-95 \mathrm{mV})$. In Fig. $4 \mathrm{c}$, it is evident that the activity increases significant with the molar concentration, however, smaller cations show a less steep increase with the concentration compared to large cations (see also Supplementary Fig. 15b, c). The differences therefore become more apparent at higher concentrations. We also note that the persistent dip seen in $0.1 \mathrm{M} \mathrm{RbOH}$ is less pronounced in $1 \mathrm{M} \mathrm{RbOH}$, hence showing that the absolute cation trend depends on the molar concentration (Supplementary Fig. 15d, e). The electrolyte $\mathrm{pH}$ was determined using a $\mathrm{pH}$-meter, which confirms that the differences between the alkali metal cations indeed are also reflected in the $\mathrm{pH}$ and not only in the OER activity (Supplementary Fig. 15f and Supplementary Table 6). Therefore, a plot of the OER activity against the electrolyte $\mathrm{pH}$, not surprisingly, almost entirely diminish the characteristic cation trend, where the activity instead increases from low to high electrolyte $\mathrm{pH}$ (see Fig. 4d, e), also confirmed in the intrinsic activity parameter $\left(\mathrm{TOF}_{\text {mass }}\right)$ at several electrode potentials (Supplementary Fig. $15 \mathrm{~h}-\mathrm{m}$ ). Note that the $\mathrm{pH}$ in $\mathrm{LiOH}$ could not be determined with a $\mathrm{pH}$-meter due to the small size of the $\mathrm{Li}^{+}$ion, which appears to have too similar transport properties through the membrane of the $\mathrm{pH}$ electrode as the proton. An approximate value of the $\mathrm{pH}$ in $\mathrm{LiOH}$ was instead obtained from the potential offset between the $\mathrm{RHE}$ and the $\mathrm{Ag} / \mathrm{AgCl}$ reference electrodes (Supplementary Note 3 and Supplementary Fig. 16a, b). The activity in $\mathrm{LiOH}$ sometimes falls a bit off the linear trend, however, we regard this to the alternative method used for determining the electrolyte $\mathrm{pH}$.

The fact that the $\mathrm{pH}$ appears to be a strong OER activity descriptor implies that the differences between the electrolyte cations can simply be explained as a response to a change in the electrolyte $\mathrm{pH}$. These findings strongly suggest that what at first glance appears as a "specific" cation effect is more likely an indirect effect due to changes in the electrolyte $\mathrm{pH}$, which has to the best of our knowledge not been recognized in earlier OER studies. An effect on the electrolyte $\mathrm{pH}$ by alkali cations has although been reported for the $\mathrm{CO}_{2}$ reduction reaction (CO2RR) on metallic $\mathrm{Ag}$ and $\mathrm{Au}$, where Sing et al. ${ }^{59}$ showed that larger cations such as $\mathrm{Cs}^{+}$improve the buffer capacity, which prevents an increase in the local $\mathrm{pH}$. This in turn decreases the faradaic 

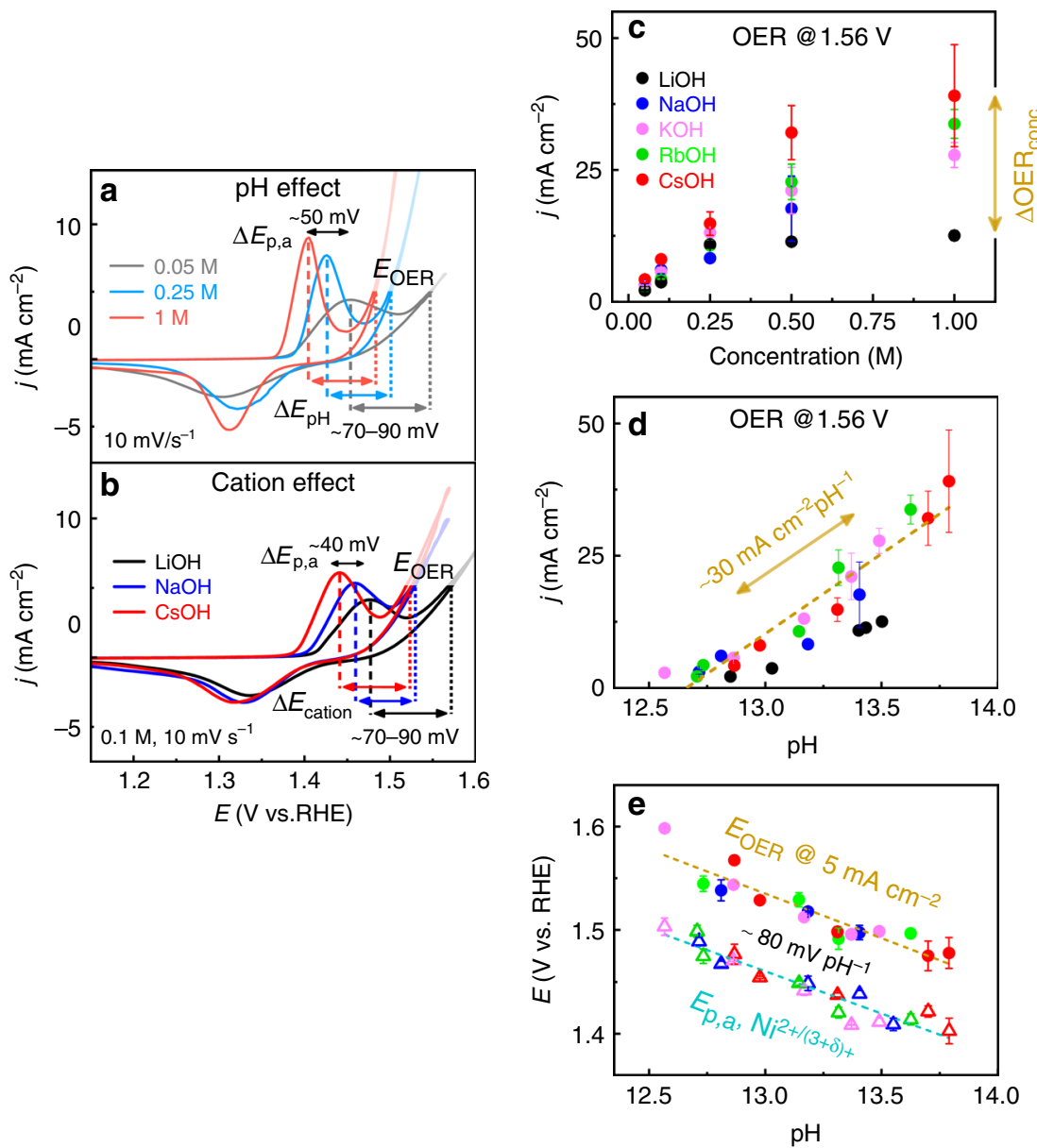

Fig. 4 The electrolyte pH as OER activity descriptor. a CVs at $10 \mathrm{mV} \mathrm{s}^{-1}$ of $\mathrm{Ni}_{65} \mathrm{Fe}_{35}(\mathrm{OOH})$ in $0.05 \mathrm{M}, 0.25 \mathrm{M}$, and $1 \mathrm{M} \mathrm{CsOH}$, to demonstrate the effect on the OER activity of increasing $\mathrm{pH}$ from low to high concentrations. $\mathbf{b} \mathrm{CVs}$ at $10 \mathrm{mV} \mathrm{s}^{-1}$ in $0.1 \mathrm{M} \mathrm{LiOH}, 0.1 \mathrm{M} \mathrm{NaOH}$, and $0.1 \mathrm{M} \mathrm{CsOH}$, to demonstrate the typical peak shift induced from small to large cations. c Current density (j) at $1.56 \mathrm{~V}$ vs. RHE plotted against the electrolyte concentration. d Current density at $1.56 \mathrm{~V}$ vs. RHE plotted against the electrolyte $\mathrm{pH}$. e The OER potential ( $\left.E_{\mathrm{OER}}\right)$ at $5 \mathrm{~mA} \mathrm{~cm} \mathrm{c}^{-2}$ (filled circles) and the anodic peak potential ( $E_{\mathrm{p}, \mathrm{a}}$ ) of the $\mathrm{Ni}^{2+} \leftrightarrow \mathrm{Ni}^{(3+\delta)+}$ redox peak from $\mathrm{CVs}$ at $10 \mathrm{mV} \mathrm{s}^{-1}$ (hollow up-pointing triangles). The color code for the alkali metal hydroxides shown in the legend in $\mathbf{c}$ also applies to $\mathbf{d}$, e. The $\mathrm{pH}$ in $\mathrm{LiOH}$ was determined with an alternative method (Supplementary Note 3), and is therefore excluded from the fit line in $\mathbf{d}$ and not shown in e for clarity. Error bars show the standard error from the overall number of measurements.

efficiencies (FE) toward $\mathrm{H}_{2}$ and $\mathrm{CH}_{4}$, and increases the $\mathrm{FE}$ for $\mathrm{CO}, \mathrm{C}_{2} \mathrm{H}_{4}$, and $\mathrm{C}_{2} \mathrm{H}_{5} \mathrm{OH}$. The $\mathrm{pH}$ effect for $\mathrm{CO} 2 \mathrm{RR}$ cannot be directly translated to alkaline OER, however, we stress that the $\mathrm{pH}$ is a likely critical parameter for reactions involving protoncoupled electron-transfer steps ${ }^{38}$.

An increase in the $\mathrm{pH}$ from $\mathrm{LiOH}$ to $\mathrm{CsOH}$ is in fact expected from their respective $\mathrm{p} K_{\mathrm{b}}$ values (Supplementary Table 6), following the increase in the basicity of the alkali hydroxide (and the decrease in Lewis acidity of the cation) from small to large cations ${ }^{16,59}$. We use the Henderson-Hasselbalch formalism to retrieve experimental $\mathrm{pH}$ values (Supplementary Note 4 and Supplementary Equations (1)-(13)). This indeed verifies that the $\mathrm{pH}$ is higher for more basic hydroxides (i.e., for bigger cations) due to a larger amount of dissociated $\mathrm{OH}^{-}$(Supplementary Fig. $15 \mathrm{~g}$ and Supplementary Table 6) ${ }^{16}$. This also confirms that larger differences are to expect first at higher concentrations, while it therefore might be challenging to capture this effect unless a wider $\mathrm{pH}$ window is considered. Despite that theory predicts an increase in $\mathrm{pH}$ from small to large cations, it cannot directly explain the deviations from the cation size trend in, e.g., $\mathrm{RbOH}$. To address this, we used ICP-OES to determine the cation concentrations in $0.1 \mathrm{M}$ and $1 \mathrm{M}$ electrolytes. This indeed shows a slightly lower than expected concentration of cations in both
$\mathrm{RbOH}$ and $\mathrm{LiOH}$, thus reflecting the variations in activity (Supplementary Table 7). This points toward actual mistakes in the electrolyte concentration rather than to an increased amount of e.g. dissolved $\mathrm{HCO}_{3}{ }^{-}$, which could also lower the $\mathrm{pH}^{7,60}$. Since the salts are very hygroscopic (especially $\mathrm{RbOH}$ and $\mathrm{CsOH}$ ), this could be one factor that contributes to further error in the concentration, as well as other dilution mistakes during preparation. It should be remembered that alkali metal cations are easily ionized elements (EIE) (especially $\mathrm{Li}^{+}$), which can also cause uncertainties in ICP-OES analysis (see further details in the Methods section). To further verify the $\mathrm{pH}$ effect, we therefore carried out experiments where the $\mathrm{pH}$ had been adjusted to nearidentical values for all alkali hydroxides. The results show that the OER activities indeed align more closely (or show a different trend) after adjusting the $\mathrm{pH}$ values (Supplementary Fig. 17). This concludes that the "characteristic" cation trend is indeed easily displaced by rather small changes in the electrolyte $\mathrm{pH}$, which further supports a $\mathrm{pH}$ effect rather than a specific cation effect. All the OER activity parameters at different $\mathrm{pH}$ are listed in Supplementary Table 8.

We observe that both the $\mathrm{Ni}^{2+/(3+\delta)+}$ redox-peak and the OER overpotential exhibit non-Nernstian $\mathrm{pH}$-slopes of ca. $-80 \mathrm{mV} \mathrm{pH}^{-1}$ in the RHE scale (Fig. 4e). The absolute pH-slopes are although 
a

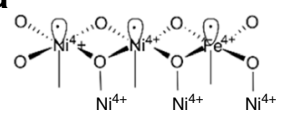

b

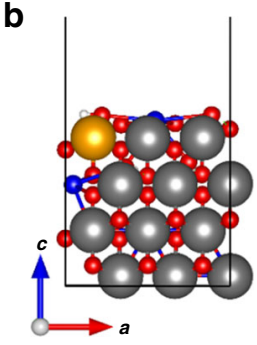

C

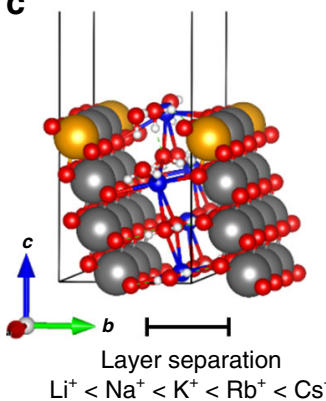

d Analyzed sites $\mathrm{Ni} / \mathrm{Fe} / \mathrm{O}(100)$

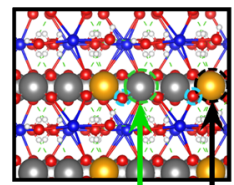

Ni next to $\mathrm{Fe}$

"activated"
$V_{\mathrm{s}}(\mathbf{r})$

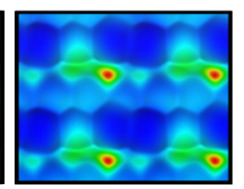

Lewis acidic


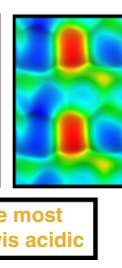

$I_{\mathrm{s}}(\mathbf{r})$

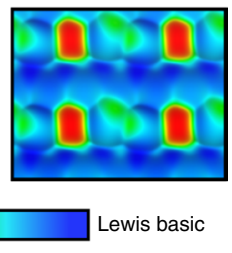

e
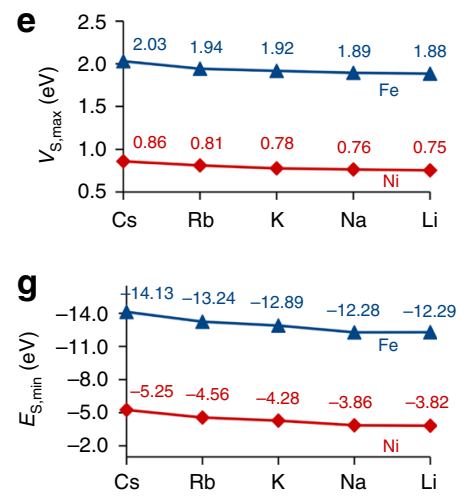

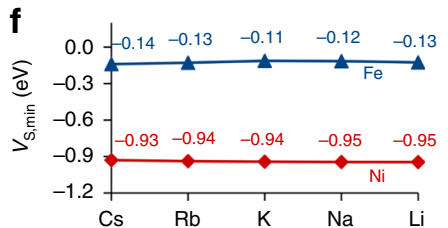

h

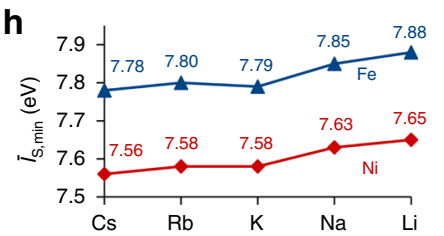

Fig. 5 Computational analysis of the reactive site. a-c Surface model of $\gamma$ - $\mathrm{Ni}(\mathrm{Fe}) \mathrm{OOH}(100)$ with intercalating water and alkali metal cations. $\mathbf{d}$ Top-view of the surface with reactivity properties estimated using DFT mapped on the 0.001 au isodensity contour is shown in. e-h Local extrema in the properties of the most activated $\mathrm{Ni} / \mathrm{O}$ and $\mathrm{Fe} / \mathrm{O}$ sites, which indicate the Lewis acidity of $\mathrm{Ni}$ and Fe sites $\left(V_{\mathrm{S}, \max }\right.$ and $\left.E_{\mathrm{S}, \min }\right)$ and Lewis basicity of $\mathrm{O}$ sites $\left(V_{\mathrm{S}, \min }\right.$ and $\left.\bar{l}_{\mathrm{S}, \min }\right)$. Color code of atomic models: $\mathrm{Ni}=$ gray, $\mathrm{Fe}=$ orange, $\mathrm{O}=$ red, Alkali $=$ blue, $\mathrm{H}=$ white.

somewhat dependent on the experimental conditions, and decrease to ca. $-40 \mathrm{mV} \mathrm{pH}^{-1}$ at slower scan-rates or at higher concentrations (Supplementary Fig. 18a-c). This is typical when mass transfer limitations are involved, as also inferred by the response of the peak separation to these parameters (Supplementary Fig. 18d, g). Since the uncompensated solution resistance ( $R_{\mathrm{u}}$ iR-drop) increases at low concentration $/ \mathrm{pH}$, this might indeed affect the kinetics (see Supplementary Table 8). More unexpected, the cathodic redox peak $\left(E_{\mathrm{p}, \mathrm{c},}\right)$ is less affected by the electrolyte $\mathrm{pH}$ than the anodic peak $\left(E_{\mathrm{p}, \mathrm{a}}\right)$, and actually exhibits a close to Nernstian $\mathrm{pH}$-slope (ca. $0 \mathrm{mV} \mathrm{pH}^{-1}$ in the RHE scale) (see Discussion, Supplementary Fig. 18b, c). The absolute level of redox charge $\left(Q_{\text {peak }}\right)$ in both the oxidation/reduction waves is on the other hand not that greatly affected by the cation or $\mathrm{pH}$ as the peak potential in accord with the XAS data above (Supplementary Fig. 18e-i), yet, both higher $\mathrm{pH}$ and slower scanrates help approach the unity value of $\sim 1.8 \mathrm{e}^{-}$per $\mathrm{Ni}^{-1}$.

Activity descriptors for alkali metal cations investigated using DFT. DFT calculations were performed of bulk $\mathrm{NiOOH}$ and of a (100) surface slab model of both $\mathrm{NiOOH}$ and $\mathrm{Fe}$-doped $\mathrm{Ni}(\mathrm{Fe})$ $\mathrm{OOH}$ in the presence of hydrated alkali metal cations (Fig. 5 and Supplementary Fig. 19). The full details of the DFT method are provided in the Methods section and Supplementary Note 5.

Our results are consistent with an increase in the cation-oxygen (X-O) coordination distances from $\mathrm{Li}^{+}$to $\mathrm{Cs}^{+}$, both to nearby water-associated oxygens and to lattice oxygens belonging to $\mathrm{Ni}$ (Fe)OOH (Supplementary Fig. 19 and Supplementary Table 9). The increase in the $\mathrm{X}-\mathrm{O}$ distance amounts ca. $4.5 \%$ from $\mathrm{Li}^{+}$to $\mathrm{Cs}^{+}$, in agreement with Zaffran et al. ${ }^{7}$ This also causes an increase in the layer separation from $\mathrm{Li}^{+}$to $\mathrm{Cs}^{+}$. Further insight regarding the catalytic activity of the alkali cation-Ni/FeOOH system was obtained from electronic structure calculations. Bader charge analysis is a standard method for assessing charge distribution within a compound ${ }^{61}$. The charges of both the $\mathrm{Ni}$ - and $\mathrm{Fe}$-sites remain essentially unaffected regardless of the alkali cation (Supplementary Fig. 20). Based on our previous knowledge, the cation should not be modifying the catalytic activity of $\mathrm{Ni}(\mathrm{Fe})$ $\mathrm{OOH}$ significantly, however, below we will more carefully evaluate the catalytic activity using a set of local reactivity properties that correlate with the Lewis basicity/acidity of a metal site. The OER reaction path has recently been shown to pass through a bifunctional mechanism relying on the cooperation between a neighboring $\mathrm{Ni}-\mathrm{O}$ Lewis acid-base pair ${ }^{30}$. This justifies that improved information of the reactivity of the $\mathrm{Ni}(\mathrm{Fe}) \mathrm{OOH}$ surface can be obtained by estimations of the local Lewis acidity and basicity of $\mathrm{Ni}, \mathrm{Fe}$ and $\mathrm{O}$ lattice sites as a function of the intercalating cation. For this purpose, we have employed three local reactivity properties (estimated by DFT calculations) that have previously been shown to correlate with the acidity/basicity of surface sites ${ }^{44-46}$. We model undercoordinated "edge sites" since these have been established as the more reactive sites in the $\mathrm{Ni}-\mathrm{Fe}$ catalyst (details on the model is provided in Supplementary Fig. 21) $31,33-35,60$. Figure 5 shows the variation in these properties for the Fe-doped version of a $\gamma-\mathrm{Ni}(\mathrm{Fe}) \mathrm{OOH}(100)$ surface, often employed as a model for the catalytic behavior of $\mathrm{Ni}-\mathrm{Fe}$ catalysts $^{28,30}$. The maximum value in the surface electrostatic potential, $V_{\mathrm{S} \text {, max }}$, at the $\mathrm{Ni}$ site gives a measure of the electrostatic contribution to the local Lewis acidity of the metal site, whereas the minimum of the surface local electron attachment energy, $E_{\mathrm{S} \text {,min }}$, reflects the charge-transfer capacity of this site. Similarly, minima in the surface electrostatic potential and the surface local average ionisation energy, $V_{\mathrm{S} \text {, min }}$ and $\bar{I}_{\mathrm{S} \text {, min }}$, respectively, indicate the electrostatic and charge-transfer contribution to the Lewis basicity of the oxygen site. We find, in agreement with the lack of a significant variation in the $\mathrm{Ni}$ and $\mathrm{Fe}$ Bader charge, that these properties show no significant variation 
with the intercalating electrolyte cation (Supplementary Table 10). The exception is the $E_{\mathrm{S}, \min }$ value, which indicates a slight increase in the Lewis acidity of the $\mathrm{Ni}$ site from small to large cation $\left(\mathrm{Li}^{+}\right.$ to $\left.\mathrm{Cs}^{+}\right)$. As will be discussed in the next paragraph, this "activation" by the alkali metal cations is relatively small in relation to the effect of, e.g., substituting $\mathrm{Ni}$ for $\mathrm{Fe}$ in the $\mathrm{NiOOH}$ lattice, so the magnitude of change from $\mathrm{Li}^{+}$to $\mathrm{Cs}^{+}$supports only a minor change in the reactivity descriptors. The Lewis basicity of the oxygen sites also remains largely unaffected by the cations (estimated from the $V_{\mathrm{S} \text {,min }}$ and $\bar{I}_{\mathrm{S}, \min }$ values in Supplementary Table 10). Thus, the reactivity indicators suggest that the alkali cations have only a minor direct promoting effect on the catalytic activity of $\mathrm{NiOOH}$.

We further model the Fe-doped $\mathrm{Ni}(\mathrm{Fe})(\mathrm{OOH})$ catalyst. When a $\mathrm{Ni}$ atom is exchanged for an $\mathrm{Fe}$ atom, the Lewis acidity of the nearby Ni-site increases (Fig. 5d-h and Supplementary Table 11). This can be exemplified using $\mathrm{K}^{+}$as an intercalating cation. The $\mathrm{Ni}$ atom next to an Fe-site becomes "activated" (i.e. stronger Lewis acid) whereas the neighboring $\mathrm{O}$ sites become slightly "deactivated" (i.e. less Lewis basic $=$ more positive $V_{\mathrm{S}, \min }$ ). This is indicated by the change in the local reactivity properties, both in the charge-transfer and electrostatic components of the Ni-site, and the electrostatic component of nearby O-sites $\left(V_{\mathrm{s}, \mathrm{min}}\right)$. The change in Lewis acidity (cf. $E_{\mathrm{S}, \min }$ ) of the Ni-site is of the same magnitude or only slightly larger than the promoting effect from $\mathrm{Li}^{+}$to $\mathrm{Cs}^{+}$. On the contrary, the Fe-site is significantly more Lewis acidic compared to the Ni-site, despite the activation of the Ni-site. This is in line with recent work by Nocera and coworkers where $\mathrm{Fe}^{3+}$ was argued to be the stronger Lewis acid and predicted to increase the acidity of the aqua/ hydroxo group connected to the $\mathrm{Ni}$-site ${ }^{24}$, which was also confirmed with situ Raman spectroscopy by Edvinsson and co-workers ${ }^{62}$. We also find that the oxygen sites connected to an Fe-site are significantly less Lewis basic than the oxygens connected to a $\mathrm{Ni}$ site. The most negative charge-transfer capacity $\left(E_{\mathrm{S}, \min }\right.$ value) is, not surprisingly, found for the sites occupied by $\mathrm{Fe}$ atoms, suggesting that these sites are most reactive of the two. The $V_{S, \max }$ value (i.e., electrostatic component) also changes in line with an increased Lewis acidity. Our results thus point toward Fe being the most Lewis acidic (and thus electrophilic) site along with less basic oxygen ligands, which could facilitate a prospect nucleophilic attack on this site. We do not find any differences in how the cations influence either $\mathrm{Ni}$ or Fe-sites, so we conclude that both sites are equally affected by alkali metal cations, which is significantly less compared to the effect of lattice $\mathrm{Fe}$ substitution. Altogether, our analysis indicates that Fe-dopants have both a direct and indirect effect on the local reactivity properties, and thus of the general reactivity of the $\mathrm{Ni}(\mathrm{Fe}) \mathrm{OOH}$ catalyst, whereas the alkali metal cations have only a comparative minor promoting effect on the OER activity.

\section{Discussion}

Several hypotheses behind the impact of electrolyte cations on the OER activity have been put forward; (I) strong non-covalent interactions between small alkali metal cations and chemisorbed species forming cation- $\mathrm{OH}_{\mathrm{ads}}$ clusters that block the active sites ${ }^{10}$. (II) perturbation of adsorption energies of the OER intermediates and the kinetics 7,50 . (III) promotion of peroxo-like "active oxygen" species by larger cations leading to a higher activity ${ }^{8,40}$. Here we put forward a new hypothesis: (IV) a change in the electrolyte $\mathrm{pH}$ caused by the differences in the Lewis acidity of the alkali cations (and thus the basicity of the alkali hydroxides) modifies the OER activity.

Our XAS and electrochemical data support that electrolyte cations affect both the $\mathrm{Ni}^{2+/(3+\delta)+}$ redox process and the OER activity, where large cations shift the oxidation and the OER process to lower potentials. This is explained by an increase in the electrolyte $\mathrm{pH}$ in the presence of larger cations due to the higher basicity of the corresponding alkali hydroxide. In recent findings by Pasquini et al. ${ }^{63}$ the catalytic rate of a $\mathrm{CoO}_{x}$ catalyst was found to be controlled by the levels of oxidized $\mathrm{Co}^{4+}$ at any defined OER overpotential. A similar scenario could prevail in our Ni-Fe catalyst, although, we do not find as strong correlation with the population of oxidized $\mathrm{Ni}^{(3+\delta)+}$ during steady-state conditions and the OER activity. We also cannot exclude a correlation between the OER activity and the redox-process due to an increase in the through-film conductivity upon formation of $\mathrm{Ni}^{3+/ 4+}$ as shown by Boettcher and co-workers ${ }^{47}$.

The metal oxidation step in the Ni-Fe catalyst occurs via a deprotonation step according to Eq. (1).

$$
\mathrm{Ni}(\mathrm{OH})_{2}+\mathrm{OH}^{-} \leftrightarrow \mathrm{NiOOH}+\mathrm{e}^{-}+\mathrm{H}_{2} \mathrm{O}
$$

It has been demonstrated that the activity and redox-process of the $\mathrm{Ni}-\mathrm{Fe}$ catalysts are sensitive to the electrolyte $\mathrm{pH}^{48}$. Both the OER activity and anodic redox-peak exhibit $\mathrm{pH}$ slopes that deviate from Nernstian ${ }^{64}$ (i.e., -40 to $-90 \mathrm{mV} \mathrm{pH}^{-1}$ on the RHE scale). Earlier studies have attributed this to non-concerted proton-electron-transfer pathways, reported as $\sim 2$ protons transferred per 1 electron $\left(\mathrm{H}^{+} / \mathrm{e}^{-} \text {ratio of } \sim 2\right)^{40,48}$. This might be explained in accordance with anionic redox-activity on the oxygen ligands as seen in soft XAS ${ }^{36,37}$, and/or by the formation of peroxo-like $\left({ }^{*} \mathrm{O}^{-}\right.$or $\left.{ }^{*} \mathrm{O}_{2}^{-}\right)$intermediates denoted as "active oxygen", seen in Raman spectroscopy as a band between $\sim 800-1150 \mathrm{~cm}^{-1} 38,39$. Concerning electrolyte cations, Garcia et al. ${ }^{8}$ found a higher intensity of this Raman band in $\mathrm{CsOH}$ compared to $\mathrm{LiOH}$, thus large cations were proposed to promote "active oxygen". We note that in earlier studies from their group this band was shown to intensify with increasing electrolyte $\mathrm{pH}^{38,39}$. Since we now know that larger electrolyte cations (i.e. $\mathrm{Cs}^{+}$) increases the electrolyte $\mathrm{pH}$, we argue that it could explain why large alkali metal cations promote the "active oxygen" band. The nature of these reactive species could in turn explain why a higher $\mathrm{pH}$ (induced by the presence of large cations) promote a higher OER activity. The non-Nernstian $\mathrm{pH}$-dependence of the cathodic redox-peak $\left(0 \mathrm{mV} \mathrm{pH}^{-1}\right.$ on the RHE-scale) has already been explained by Merrill et al. ${ }^{41}$, where $\mathrm{NiOOH}$ was found to follow a different charge and discharge mechanism. The "active oxygen" species formed during charge, vanish before reaching the onset of the reduction wave, whereby the discharge occurrs via a $\mathrm{NiO}\left(\mathrm{H}_{2} \mathrm{O}\right)$ intermediate before reduced back to $\mathrm{Ni}(\mathrm{OH})_{2}$, hence explaining the difference in $\mathrm{pH}$-slopes between the oxidation/ reduction waves.

Other considerations regarding electrolyte cations concern the water solvation shell, which is more strongly held around smaller cations $\left(\mathrm{Li}^{+}\right)$compared to larger cations $\left(\mathrm{Cs}^{+}\right)^{17}$, whereby the native $\mathrm{H}$-bonded network of water is disrupted to a higher extent in the presence of smaller cations. This has implications on the diffusion rate and water reorientation times, which is usually slower in the presence of small cations ${ }^{14,65}$, which also affects the proton-transfer kinetics ${ }^{66}$. In a study by Ledezma-Yanez et al. ${ }^{67}$ a correlation between the interfacial water reorganization and the activity for the hydrogen evolution reaction (HER) on metallic Pt was established, where a faster water reorganization was found to benefit a higher HER activity via more efficeint proton/ hydroxide transfer through the electric double layer. Huang et al. ${ }^{18}$ showed that easier water reorganization around a redoxactive metal center such as ferri/ferrocyanide in the presence of large cations, is related to a higher exchange current density and a lower reaction entropy and to faster electron transfer kinetics. We therefore cannot exclude that there are some specific cation effects in addition to the $\mathrm{pH}$ effects due to non-covalent interactions between cations and water.

Our DFT-derived reactivity descriptors show that alkali metal cations have a rather small effect on the local reactivity properties 
of the $\mathrm{Ni} / \mathrm{FeOOH}$ surface compared to e.g. Fe-substitution, which activates Ni-sites by increasing the Lewis acidity. Despite this, the Fe-sites remain the most Lewis acidic site (and thus the most "reactive" site). In contrast to the rather large effect of Fe-substitution on the reactivity descriptors in comparison to the alkali cations, there is still a small increase in the acidity for both $\mathrm{Ni}$ and $\mathrm{Fe}$ sites between the two extremes ( $\mathrm{Li}+$ to $\mathrm{Cs}+$ ). Since this effect is relatively small, it is likely to go unnoticed unless it exceeds the effect of the electrolyte $\mathrm{pH}$. In catalysis, it should also be kept in mind that "optimal" activity is often associated with a moderate reactivity (cf. sweet spot in adsorption energy in a Volcano plot).

In conclusion, we demonstrate that the effect of alkali metal cations on the OER activity of the $\mathrm{Ni}_{65} \mathrm{Fe}_{35}(\mathrm{OOH})$ catalyst can be explained by differenes in the electrolyte $\mathrm{pH}$, supported by the directional shift of the $\mathrm{Ni}^{2+} \rightarrow \mathrm{Ni}^{3+/ 4+}$ redox-peak and the OER activity. Since the basicity increases in the order $\mathrm{LiOH}<$ $\mathrm{NaOH}<\mathrm{KOH}<\mathrm{RbOH}<\mathrm{CsOH}$ following the cation size (explained by their $\mathrm{p} K_{\mathrm{b}}$ values), the electrolyte $\mathrm{pH}$ increases accordingly from small to large alkali metal cations due to an increase in the amount of dissociated $\mathrm{OH}^{-}$. Since the OER activity is sensitive to $\mathrm{pH}$, this is able to explain previously puzzling discrepancies between the trend in cation size and the OER activity, since any factor introducing uncertainties in the $\mathrm{OH}^{-}$concentration (or electrolyte concentration) can affect the OER activity. Our DFT-derived reactivity descriptors further support that alkali metal cations do not significantly alter the intrinsic reactivity properties of either $\mathrm{Ni}, \mathrm{Fe}$, or $\mathrm{O}$ lattice in contrast to $\mathrm{Fe}$ substitution, which instead increases the Lewis acidity of neighboring Ni-sites (although Fe remains the most Lewis acidic site). The alkali cations are therefore unlikely to account for the differences in the OER activity. Thus, our DFT results are in line with the experimental findings that the electrolyte $\mathrm{pH}$ constitutes the strongest activity descriptor. Future studies therefore need to explore possible $\mathrm{pH}$ effects in oxide-derived catalysts in striving for understanding the role of alkali metal cations in OER electrocatalysis.

\begin{abstract}
Methods
Ni-Fe catalyst depostition and electrolyte preparation. The $\mathrm{Ni}-\mathrm{Fe}(\mathrm{OOH})$ catalyst was prepared by electrodeposition on $\sim 25 \mathrm{~mm}$ thick conductive graphene sheets (Graphene Supermarket) roughened with sand paper; without this step, the adhesion and stability of the films were poor on the smooth surface. The deposition solution constituted $9 \mathrm{~mL}$ of $50 \mathrm{mM} \mathrm{Ni}\left(\mathrm{NO}_{3}\right)_{2} \cdot 6 \mathrm{H}_{2} \mathrm{O}(99.999 \%$ trace metals basis, Sigma-Aldrich) and $1 \mathrm{~mL}$ of $50 \mathrm{mM} \mathrm{Fe}\left(\mathrm{NO}_{3}\right)_{3} \cdot 9 \mathrm{H}_{2} \mathrm{O}(\geq 99.999 \%$ trace metals basis, Sigma-Aldrich); Fe tends to deposit easier than Ni. The catalyst films were deposited galvanostatically on a geometric area of ca. $0.4 \mathrm{~cm}^{2}$ using a 2-electrode setup where a fine Pt-coil served as counter electrode. A current density of $-2.5 \mathrm{~mA} \mathrm{~cm}^{-2}$ was applied for $113 \mathrm{~s}$, using a Bio-Logic SP-200 potentiostat. This resulted in a film with a Ni:Fe stoichiometry of 65:35 at. \%, and a geometric metal loading (with respect to both $\mathrm{Ni}$ and Fe content) of $\sim 25 \pm 2 \mu \mathrm{g} \mathrm{cm}^{-2}$. Another $\mathrm{Ni}_{75} \mathrm{Fe}_{25}$ catalyst with a metal loading of $3 \pm 1 \mu \mathrm{g} \mathrm{cm}{ }^{-2}(\sim 50 \mathrm{~nm}$ thick) was instead prepared from $10 \mathrm{mM}$ deposition solutions including $100 \mathrm{mM} \mathrm{KNO}_{3}$ supporting electrolyte. The alkali metal hydroxides used for activity investigations were the following; $\mathrm{LiOH}$ (monohydrate, $99.995 \%$ trace metals basis, Sigma-Aldrich), $\mathrm{NaOH}$ (monohydrate $\geq 99.996 \%$ metals basis, Alfa-Aesar), $\mathrm{KOH}$ (semiconductor grade, pellets, 99.99\%, Sigma-Aldrich), RbOH (hydrate, Sigma-Aldrich), $\mathrm{CsOH}$ (monohydrate, $99.95 \%$ trace metals basis, Sigma-Aldrich). Unless otherwise stated, the alkali hydroxides were stripped of Fe-impurities according to a modified purification method reported by Boettcher and co-workers (Supplementary Note 1$)^{47}$.
\end{abstract}

In situ XAS at the influence of alkali metal cations. XAS was acquired at the $\mathrm{Ni}$ and Fe $K$-edges at the P64 beamline at Petra III (DESY, Hamburg, Germany) during in situ conditions. The $\mathrm{Ni}_{65} \mathrm{Fe}_{35}(\mathrm{OOH})$ catalyst was investigated in purified $0.1 \mathrm{M}$ alkali hydroxides; $\mathrm{LiOH}, \mathrm{NaOH}, \mathrm{KOH}, \mathrm{RbOH}$, and $\mathrm{CsOH}$. The electrochemical cell constituted a single compartment 3 -electrode cell, with an outer diameter of $50 \mathrm{~mm}$, an inner diameter of $25 \mathrm{~mm}$, and an X-ray window of $6 \times$ $6 \mathrm{~mm}$ mounted $\sim 20 \mathrm{~mm}$ from the bottom. The working electrode was an Ni-Fe $(\mathrm{OOH} /$ graphene sheet connected via a Cu-clip from the upper backside, a Pt-mesh served as counter electrode, and a leak-free $\mathrm{Ag} / \mathrm{AgCl}$ as reference electrode. All measurements were controlled using a Bio-Logic SP-200 potentiostat. Spectra (XANES/EXAFS) were collected at different potentials; 1.1, 1.34, 1.41, 1.48, 1.56, $1.66 \mathrm{~V}$ and return to $1.1 \mathrm{~V}$ vs. RHE. The uncompensated solution resistance $\left(\mathrm{R}_{\mathrm{u}}\right.$, iR-drop) was determined individually using electrochemical impedance spectroscopy (EIS) at $10 \mathrm{kHz}$, applying $85 \%$ automatic iR-compensation (ZIR method) in the EC-Lab software. Additional 5\% was compensated afterwards to total level of $90 \%$. More than $90 \%$ was not possible due to overcompensation effects. A typical value of the iR-drop in the in situ XAS setup was $25 \mathrm{Ohm}$ in $0.1 \mathrm{M}$ electrolytes. The spectra at the $\mathrm{Ni}$ and $\mathrm{Fe} K$-edges were collected in pairs before stepping to the next potential, where typically 2-5 consecutive spectra were collected for each edge. The incoming X-ray beam was set to an incident angle of $\sim 10^{\circ}$, and the fluorescence collected from the back-side using a passivated implanted planar silicon (PIPS) detector. A second data set was collected at the $\mathrm{Ni}$ $K$-edges at the SuperXAS-X10DA beamline at Swiss Light Source (SLS) (PSI, Villigen, Switzerland), and is shown in Supplementary Fig. 11. For these measurements, a Si-drift detector with five crystals was used instead. More details on the XAS data processing and EXAFS simulations are provided in Supplementary Note 2. All electrode potentials were converted to the RHE scale afterwards, where the offsets were obtained by calibration against an RHE electrode.

\section{Correlations between OER activity and electrolyte pH measured "in house".} All "in house" electrochemical characterization was carried out in 3-electrode configuration using the same electrochemical cell as used for in situ XAS. The cell setup differed mainly in the choice of the reference electrode, which was a RHE electrode in order to avoid unknown shifts in the potential-scale due to small differences in $\mathrm{pH}$ between the alkali hydroxides, and we applied constant purging with $\mathrm{N}_{2}$. The employed RHE electrode was manufactured from a hollow glass rod $(\varnothing=8 \mathrm{~mm})$ with a coiled Pt-wire inside. The rod was sealed at the top around the Pt-wire using a hot flame. The cavity of the RHE was filled with the respective alkali hydroxides ( $\mathrm{LiOH}$, $\mathrm{NaOH}, \mathrm{KOH}, \mathrm{RbOH}, \mathrm{CsOH}$ ) that had been degassed with $\mathrm{N}_{2}$ for $\sim 10$ min to remove $\mathrm{O}_{2}$. Hydrogen $\left(\mathrm{H}_{2}\right)$ was evolved on the inner Pt-coil by applying $-5 \mathrm{~V}$ for about $\sim 30-60 \mathrm{~s}$. The OER activity was investigated in several electrolyte concentrations; 0.05 $\mathrm{M}, 0.1 \mathrm{M}, 0.25 \mathrm{M}, 0.5 \mathrm{M}$, and $1 \mathrm{M}$ of $\mathrm{LiOH}, \mathrm{NaOH}, \mathrm{KOH}, \mathrm{RbOH}$, and $\mathrm{CsOH}$. The alkali hydroxides had been purified unless otherwise stated (see Supplementary Note 1). Fresh catalyst films were always used for different cations, as well as for repetitions of the same cation. The electrolyte $\mathrm{pH}$ was determined using a standard pH-meter pre-calibrated between pH 9-13 (pH-electrode LE438, Mettler Toledo). For some measurements, a specialized alkali $\mathrm{pH}$-electrode with a ceramic membrane was employed (InLab Routine ${ }^{\circledast}$ Pro-ISM, Mettler Toledo). The $\mathrm{pH}$ of LiOH could not be determined with any of these $\mathrm{pH}$-electrodes since the small $\mathrm{Li}^{+}$ion seems to have too similar transport properties to the proton. The experimental $\mathrm{pH}$ of $\mathrm{LiOH}$ was instead estimated using the potential difference between the RHE electrode and the $\mathrm{Ag} / \mathrm{AgCl}$ reference electrodes, by constructing a calibration curve using commercial solutions with known $\mathrm{pH}$ (Supplementary Note 3). Tafel slopes were collected during steadystate conditions by applying chronoamperometric steps for 250-300 s, increasing by 5-50 mV per step. The first $120 \mathrm{~s}$ were discarded from the average to assure steadystate conditions. Automatic iR-compensation was applied to all potentiodynamic and potentiostatic techniques to a total level of $90 \%$; $85 \%$ automatic, and $5 \%$ manual compensation.

Elemental analysis. Inductively coupled plasma optical emission spectroscopy (ICP-OES) was used to determine the metal loading and compositions in the $\mathrm{Ni}-\mathrm{Fe}$ catalyst and the concentration of alkali cations in the electrolytes, using a Thermo Fisher Scientific iCAP 6000-series spectrometer. The Ni-Fe catalyst films were dissolved in $200 \mu \mathrm{lNO}_{3}(70 \%), 200 \mu \mathrm{H} \mathrm{H}_{2} \mathrm{SO}_{4}(>97.5 \%)$, and $500 \mu$ $\mathrm{HCl}(37 \%)$ (all ACS reagent grade, Sigma-Aldrich). The samples were left for 1-2 $\mathrm{h}$ to digest into its elements, and then diluted to a total volume of $5 \mathrm{~mL}$ using ultrapure MilliQ-water $(18 \mathrm{M} \Omega \mathrm{cm})$. The alkali hydroxides were instead diluted with MilliQ-water to a final concentration of $12.5 \mathrm{mg} / \mathrm{L}$. The dilution factors for the $1 \mathrm{M}$ hydroxides were following: $\mathrm{LiOH}(3356 \mathrm{x}), \mathrm{NaOH}(4641 \mathrm{x}), \mathrm{KOH}$ (4489x), and $\mathrm{RbOH}(8198 \mathrm{x})$, and $\mathrm{CsOH}(13434 \mathrm{x})$ and the $0.1 \mathrm{M}$ solutions were diluted 10 times less. Low concentrations minimize the easy ionizable effect (EIE). ICP standards were prepared from a multielement standard solution (100 $\mathrm{mg} / \mathrm{L}$, TraceCERT, Sigma-Aldrich), and diluted in a series of $0.05,0.1,0.5,1,10$, and $20 \mathrm{mg} / \mathrm{L}$. Note that the concentration of $\mathrm{Cs}$ in $\mathrm{CsOH}$ was not successfully determined because of near zero-emission intensity. To scan for trace impurities the alkali hydroxides were kept more concentrated $(\sim 1000 \mathrm{mg} / \mathrm{L})$. We assume that only ionic impurities in the solution is of importance. The analysis was carried out using an Avio 200 spectrometer (PerkinElmer), and a multielement standard solution with a concentration of $10 \mathrm{mg} / \mathrm{L}$ (PerkinElmer) used without further dilution. The following emission wavelengths were analyzed; $\mathrm{Li}$ (460.2 $\mathrm{nm}, 670.8 \mathrm{~nm}), \mathrm{Na}(589.6 \mathrm{~nm}), \mathrm{K}(766.5 \mathrm{~nm}, 769.8 \mathrm{~nm}), \mathrm{Rb}(780.0 \mathrm{~nm}), \mathrm{Cs}$ $(672.3 \mathrm{~nm}, 455.5 \mathrm{~nm}), \mathrm{Ni}(231.6 \mathrm{~nm})$, and Fe $(238.2 \mathrm{~nm})$. The hydroxides were also scanned for additional impurites; Ca (393.3 nm), Mn (257.6 nm), Co (228.6 $\mathrm{nm}), \mathrm{Cu}(327.4 \mathrm{~nm})$, and $\mathrm{Zn}(206.2 \mathrm{~nm})$.

Scanning electron microscopy (SEM) and energy-dispersive X-ray spectroscopy (EDS). SEM was carried out using a JSM-7000F microscope (JEOL). Additional SEM and elemental mappings were carried out using a LEO1550 microscopy (Zeiss). For images, the working distance was set between $5.5-10 \mathrm{~mm}$ and the accelerating voltage to $3-10 \mathrm{kV}$ depending on the information depth and the microscope. To determine the elemental compositions, EDS was carried out at an accelerating voltage of $15-20 \mathrm{kV}$ using the built-in EDS detector in the 
respective microscopes (both from Oxford Instruments). The analysis was carried out using either the INCA or AZtec software packages (Oxford Instruments).

DFT computational details. Atomic models of the alkali cation impregnated $\mathrm{NiOOH}$ bulk material were generated from the $\mathrm{Na}^{+}$-containing structures optimized by Zaffran et al. ${ }^{7}$. The $\mathrm{NiOOH}$ and $\mathrm{Fe}$-substituted $\mathrm{Ni}(\mathrm{Fe}) \mathrm{OOH}$ has a layered structure, with $\mathrm{H}_{2} \mathrm{O}$ and alkali cations residing in-between the crystal $\mathrm{Ni} / \mathrm{FeOOH}$ sheets (Supplementary Figs. 19 and 21). The bulk parameters were reoptimized for the full series of alkali metal cations from $\mathrm{Li}^{+}$to $\mathrm{Cs}^{+}\left(\right.$and $\mathrm{Fr}^{+}$). Surface slab models of the (100) facet, often used as a representative surface for the $\mathrm{Ni} / \mathrm{FeOOH}$ material, were constructed from the optimized bulk material. Four layers of $\mathrm{Ni} /$ $\mathrm{FeOOH}$ were used in the slab models employing a $(1 \times 1)$ surface supercell, and a vacuum distance of $17 \AA$. Only the top layer was allowed to relax in the calculations. The surface exposes three $\mathrm{Ni}^{3+/ 4+}$ ions. For comparison, we exchanged one third of these with $\mathrm{Fe}^{3+/ 4+}$ at different positions in the analysis of surface properties (vide infra). Periodic and spin-polarized DFT calculations were performed with the Vienna Ab-initio Simulation Package (VASP) ${ }^{68}$. The PBE exchangecorrelation functional was used throughout, employing the Hubbard $+\mathrm{U}$ corrections ${ }^{69}$ for the $\mathrm{Ni}$ and $\mathrm{Fe} 3 \mathrm{~d}$ states with the $\mathrm{U}-\mathrm{j}$ values 6.0 and $3.5 \mathrm{eV}$, respectively, as suggested by Zaffran et al. ${ }^{7}$. The core states were represented by standard PAW potentials $^{70,71}$, whereas the valence electrons (Li: $1 \mathrm{~s} 2 \mathrm{~s}$; alkali[p=period]: $(\mathrm{p}-1) \mathrm{s}$ (p-1)p ps; Ni/Fe: 3p 3d 4 s; O: $2 \mathrm{~s} 2 \mathrm{p} ; \mathrm{H}: 1 \mathrm{~s}$ ) where expanded on a plane-wave basis with an energy cut-off of $800 \mathrm{eV}$ for the bulk calculations and $600 \mathrm{eV}$ for the surface slabs. The $\mathbf{k}$-space was sampled using the tetrahedron method with Blöchl corrections $^{72}$ on $8 \times 6 \times 4$ and $4 \times 6 \times 1 \mathbf{k}$-meshes for the bulk and surface calculations, respectively. In the geometrical optimizations, the forces were relaxed to $<0.01 \mathrm{eV} / \AA$, while the electronic convergence criterion was set to $1 \mathrm{e}^{-6} \mathrm{eV}$. More details on the specific DFT-derived reactivity descriptors are found in Supplementary Note 5 . The robustness of the computed results was tested by evaluating the effect of including empirical dispersion corrections via the $\mathrm{D} 3(\mathrm{BJ})$ method $^{73,74}$, and implicit solvation following the VASPSOL protocol ${ }^{75}$. The effect of dispersion corrections on the predicted reactivates is found to be negligible (Supplementary Tables 12 and 13). Whereas inclusion of solvation is found to alter the absolute values of the local reactivity properties, the relative trend over the series of cations remains the same with or without solvation (Supplementary Table 14).

\section{Data availability}

All data in this manuscript can be made available upon request to the corresponding authors.

Received: 13 March 2020; Accepted: 26 October 2020;

Published online: 02 December 2020

\section{References}

1. Lewis, N. S. \& Nocera, D. G. Powering the planet: chemical challenges in solar energy utilization. Proc. Natl Acad. Sci. USA 103, 15729-15735 (2006).

2. Park, S., Shao, Y., Liu, J. \& Wang, Y. Oxygen electrocatalysts for water electrolyzers and reversible fuel cells: status and perspective. Energy Environ. Sci. 5, 9331-9344 (2012).

3. Stamenkovic, V. R., Strmcnik, D., Lopes, P. P. \& Markovic, N. M. Energy and fuels from electrochemical interfaces. Nat. Mater. 16, 57 (2016).

4. Busch, M. et al. Beyond the top of the volcano? - A unified approach to electrocatalytic oxygen reduction and oxygen evolution. Nano Energy 29, 126-135 (2016).

5. Kim, J. S., Kim, B., Kim, H. \& Kang, K. Recent progress on multimetal oxide catalysts for the oxygen evolution reaction. Adv. Energy Mater. 8, 26 (2018).

6. Dionigi, F. \& Strasser, P. NiFe-based (oxy)hydroxide catalysts for oxygen evolution reaction in non-acidic electrolytes. Adv. Energy Mater. 6, 1600621 (2016).

7. Zaffran, J. et al. Influence of electrolyte cations on $\mathrm{Ni}(\mathrm{Fe}) \mathrm{OOH}$ catalyzed oxygen evolution reaction. Chem. Mater. 29, 4761-4767 (2017).

8. Garcia, A. C., Touzalin, T., Nieuwland, C., Perini, N. \& Koper, M. T. M. Enhancement of oxygen evolution activity of nickel oxyhydroxide by electrolyte alkali cations. Angew. Chem. Int. Ed. 58, 12999-13003 (2019).

9. Ding, C. et al. Abnormal effects of cations $(\mathrm{Li}+, \mathrm{Na}+$, and $\mathrm{K}+$ ) on photoelectrochemical and electrocatalytic water splitting. J. Phys. Chem. B 119, 3560-3566 (2015).

10. Strmcnik, D. et al. The role of non-covalent interactions in electrocatalytic fuel-cell reactions on platinum. Nat. Chem. 1, 466 (2009).

11. Tymoczko, J., Colic, V., Ganassin, A., Schuhmann, W. \& Bandarenka, A. S. Influence of the alkali metal cations on the activity of $\mathrm{Pt}(111)$ towards model electrocatalytic reactions in acidic sulfuric media. Catal. Today 244, 96-102 (2015).

12. García, N., Climent, V., Orts, J. M., Feliu, J. M. \& Aldaz, A. Effect of pH and alkaline metal cations on the voltammetry of $\mathrm{Pt}(111)$ single crystal electrodes in sulfuric acid solution. ChemPhysChem 5, 1221-1227 (2004).
13. Li, K. \& Xue, D. Estimation of electronegativity values of elements in different valence states. J. Phys. Chem. A 110, 11332-11337 (2006).

14. Marcus, Y. \& Marcus, Y. Ions in Solution and their Solvation (John Wiley \& Sons, Inc., New Jersey, 2015).

15. Searles, S. K., Dzidic, I. \& Kebarle, P. Proton affinities of the alkali hydroxides. J. Am. Chem. Soc. 91, 2810-2811 (1969)

16. Baes, C. F. \& Mesmer, R. S. The Hydrolysis of Cations. Berichte der Bunsengesellschaft für Physikalische Chemie Vol. 81 (John Wiley \& Sons, Inc., New Jersey, 1976).

17. Mähler, J. \& Persson, I. A study of the hydration of the alkali metal ions in aqueous solution. Inorg. Chem. 51, 425-438 (2012).

18. Huang, B. et al. Non-covalent interactions in electrochemical reactions and implications in clean energy applications. Phys. Chem. Chem. Phys. 20, 15680-15686 (2018)

19. Michael, J. D. et al. Alkaline electrolyte and Fe impurity effects on the performance and active-phase structure of $\mathrm{NiOOH}$ thin films for OER catalysis applications. J. Phys. Chem. C 119, 11475-11481 (2015).

20. Friebel, D. et al. Identification of highly active $\mathrm{Fe}$ sites in $(\mathrm{Ni}, \mathrm{Fe}) \mathrm{OOH}$ for electrocatalytic water splitting. J. Am. Chem. Soc. 137, 1305-1313 (2015).

21. González-Flores, D. et al. Nickel-iron catalysts for electrochemical water oxidation - redox synergism investigated by in situ X-ray spectroscopy with millisecond time resolution. Sustain. Energy Fuels 2, 1986-1994 (2018).

22. Görlin, M. et al. Oxygen evolution reaction dynamics, faradaic charge efficiency, and the active metal redox states of Ni-Fe oxide water splitting electrocatalysts. J. Am. Chem. Soc. 138, 5603-5614 (2016).

23. Smith, R. D. L. et al. Geometric distortions in nickel (oxy)hydroxide electrocatalysts by redox inactive iron ions. Energy Environ. Sci. 11, 2476-2485 (2018)

24. $\mathrm{Li}, \mathrm{N}$. et al. Influence of iron doping on tetravalent nickel content in catalytic oxygen evolving films. Proc. Natl Acad. Sci. USA 114, 1486-1491 (2017).

25. Wang, D. et al. In situ X-ray absorption near-edge structure study of advanced nife(oh)x electrocatalyst on carbon paper for water oxidation. J. Phys. Chem. C 119, 19573-19583 (2015).

26. Chen, J. Y. C. et al. Operando analysis of $\mathrm{NiFe}$ and Fe oxyhydroxide electrocatalysts for water oxidation: detection of $\mathrm{Fe}^{4+}$ by Mössbauer spectroscopy. J. Am. Chem. Soc. 137, 15090-15093 (2015).

27. Fidelsky, V. \& Toroker, M. C. The secret behind the success of doping nickel oxyhydroxide with iron. Phys. Chem. Chem. Phys. 19, 7491-7497 (2017)

28. Xiao, H., Shin, H. \& Goddard, W. A. Synergy between $\mathrm{Fe}$ and $\mathrm{Ni}$ in the optimal performance of $(\mathrm{Ni}, \mathrm{Fe}) \mathrm{OOH}$ catalysts for the oxygen evolution reaction. Proc. Natl Acad. Sci. USA 115, 5872-5877 (2018).

29. Song, F. et al. An unconventional iron nickel catalyst for the oxygen evolution reaction. ACS Cent. Sci. 5, 558-568 (2019).

30. Vandichel, M., Busch, M. \& Laasonen, K. Oxygen evolution on metal-oxyhydroxides: beneficial role of mixing $\mathrm{Fe}, \mathrm{Co}, \mathrm{Ni}$ explained via bifunctional edge/acceptor route. ChemCatChem 12, 1436-1442 (2019).

31. Dionigi, F. et al. In-situ structure and catalytic mechanism of NiFe and $\mathrm{CoFe}$ layered double hydroxides during oxygen evolution. Nat. Commun. 11, 2522 (2020)

32. Ahn, H. S. \& Bard, A. J. Surface interrogation scanning electrochemical microscopy of Nil-xFexOOH $(0<\mathrm{x}<0.27)$ oxygen evolving catalyst: kinetics of the "fast" iron sites. J. Am. Chem. Soc. 138, 313-318 (2016).

33. Lee, S., Banjac, K., Lingenfelder, M. \& Hu, X. Oxygen isotope labeling experiments reveal different reaction sites for the oxygen evolution reaction on nickel and nickel iron oxides. Angew. Chem. Int. Ed. 58, 10295-10299 (2019).

34. Roy, C. et al. Impact of nanoparticle size and lattice oxygen on water oxidation on NiFeOxHy. Nat. Catal. 1, 820-829 (2018).

35. Burke Stevens, M., Trang, C. D. M., Enman, L. J., Deng, J. \& Boettcher, S. W. Reactive $\mathrm{Fe}$-sites in $\mathrm{Ni} / \mathrm{Fe}$ (oxy)hydroxide are responsible for exceptional oxygen electrocatalysis activity. J. Am. Chem. Soc. 139, 11361-11364 (2017).

36. Drevon, D. et al. Uncovering the role of oxygen in $\mathrm{Ni}-\mathrm{Fe}(\mathrm{OxHy})$ electrocatalysts using in situ soft X-ray absorption spectroscopy during the oxygen evolution reaction. Sci. Rep. 9, 1532 (2019).

37. Yoshida, M. et al. Direct observation of active nickel oxide cluster in nickel-borate electrocatalyst for water oxidation by in situ O K-edge X-ray absorption spectroscopy. J. Phys. Chem. C 119, 19279-19286 (2015).

38. Diaz-Morales, O., Ferrus-Suspedra, D. \& Koper, M. T. M. The importance of nickel oxyhydroxide deprotonation on its activity towards electrochemical water oxidation. Chem. Sci. 7, 2639-2645 (2016).

39. Trześniewski, B. J. et al. In-situ observation of active oxygen species in $\mathrm{Fe}$ containing Ni-based oxygen evolution catalysts: the effect of $\mathrm{pH}$ on electrochemical activity. J. Am. Chem. Soc. 137, 15112-15121 (2015).

40. Yang, C., Fontaine, O., Tarascon, J.-M. \& Grimaud, A. Chemical recognition of active oxygen species on the surface of oxygen evolution reaction electrocatalysts. Angew. Chem. Int. Ed. 56, 8652-8656 (2017).

41. Merrill, M., Worsley, M., Wittstock, A., Biener, J. \& Stadermann, M. Determination of the "NiOOH" charge and discharge mechanisms at ideal activity. J. Electroanal. Chem. 717-718, 177-188 (2014). 
42. Brinck, T., Carlqvist, P. \& Stenlid, J. H. Local electron attachment energy and its use for predicting nucleophilic reactions and halogen bonding. J. Phys. Chem. A 120, 10023-10032 (2016).

43. Sjoberg, P., Murray, J. S., Brinck, T. \& Politzer, P. Average local ionization energies on the molecular surfaces of aromatic systems as guides to chemical reactivity. Can. J. Chem. 68, 1440-1443 (1990).

44. Halldin Stenlid, J., Johansson, A. J. \& Brinck, T. The local electron attachment energy and the electrostatic potential as descriptors of surface-adsorbate interactions. Phys. Chem. Chem. Phys. 21, 17001-17009 (2019).

45. Brinck, T. \& Stenlid, J. H. The molecular surface property approach: a guide to chemical interactions in chemistry, medicine, and material. Sci. Adv. Theory Simul. 2, 1800149 (2019).

46. Tissot, $\mathrm{H}$. et al. Interaction of atomic hydrogen with the $\mathrm{Cu}_{2} \mathrm{O}(100)$ and (111) surfaces. J. Phys. Chem. C 123, 22172-22180 (2019).

47. Trotochaud, L., Young, S. L., Ranney, J. K. \& Boettcher, S. W. Nickel-iron oxyhydroxide oxygen-evolution electrocatalysts: the role of intentional and incidental iron incorporation. J. Am. Chem. Soc. 136, 6744-6753 (2014).

48. Görlin, M. et al. Tracking catalyst redox states and reaction dynamics in $\mathrm{Ni}-\mathrm{Fe}$ oxyhydroxide oxygen evolution reaction electrocatalysts: the role of catalyst support and electrolyte pH. J. Am. Chem. Soc. 139, 2070-2082 (2017).

49. Batchellor, A. S. \& Boettcher, S. W. Pulse-electrodeposited Ni-Fe (oxy) hydroxide oxygen evolution electrocatalysts with high geometric and intrinsic activities at large mass loadings. ACS Catal. 5, 6680-6689 (2015).

50. Suntivich, J., Perry, E. E., Gasteiger, H. A. \& Shao-Horn, Y. The influence of the cation on the oxygen reduction and evolution activities of oxide surfaces in alkaline electrolyte. Electrocatalysis 4, 49-55 (2013).

51. Louie, M. W. \& Bell, A. T. An investigation of thin-film Ni-Fe oxide catalysts for the electrochemical evolution of oxygen. J. Am. Chem. Soc. 135, 12329-12337 (2013).

52. Klaus, S., Louie, M. W., Trotochaud, L. \& Bell, A. T. Role of catalyst preparation on the electrocatalytic activity of $\mathrm{Nil}-\mathrm{xFexOOH}$ for the oxygen evolution reaction. J. Phys. Chem. C 119, 18303-18316 (2015).

53. de Groot, F., Vankó, G. \& Glatzel, P. The 1s x-ray absorption pre-edge structures in transition metal oxides. J. Phys. Condens. Matter 21, 104207 (2009).

54. Rehr, J. J., Kas, J. J., Vila, F. D., Prange, M. P. \& Jorissen, K. Parameter-free calculations of X-ray spectra with FEFF9. Phys. Chem. Chem. Phys. 12, 5503-5513 (2010).

55. Hunter, B. M. et al. Trapping an iron(VI) water-splitting intermediate in nonaqueous media. Joule 2, 747-763 (2018).

56. Hunter, B., Winkler, J. \& Gray, H. Iron is the active site in nickel/iron water oxidation electrocatalysts. Molecules 23, 903 (2018).

57. Sanson, A. et al. Local structure and spin transition in $\mathrm{Fe}_{2} \mathrm{O}_{3}$ hematite at high pressure. Phys. Rev. B 94, 14112 (2016).

58. Giordano, L. et al. pH dependence of OER activity of oxides: current and future perspectives. Catal. Today 262, 2-10 (2016).

59. Singh, M. R., Kwon, Y., Lum, Y., Ager, J. W. \& Bell, A. T. Hydrolysis of electrolyte cations enhances the electrochemical reduction of $\mathrm{CO} 2$ over Ag and Cu. J. Am. Chem. Soc. 138, 13006-13012 (2016).

60. Hunter, B. M., Hieringer, W., Winkler, J. R., Gray, H. B. \& Müller, A. M. Effect of interlayer anions on $[\mathrm{NiFe}]-\mathrm{LDH}$ nanosheet water oxidation activity. Energy Environ. Sci. 9, 1734-1743 (2016).

61. Bader, R. F. W. Atoms in Molecules. A Quantum Theory (Oxford University Press, Oxford, 1994).

62. Qiu, Z., Ma, Y. \& Edvinsson, T. In operando Raman investigation of Fe doping influence on catalytic $\mathrm{NiO}$ intermediates for enhanced overall water splitting. Nano Energy 66, 104118 (2019).

63. Pasquini, C. et al. H/D isotope effects reveal factors controlling catalytic activity in Co-based oxides for water oxidation. J. Am. Chem. Soc. 141, 2938-2948 (2019).

64. Rossmeisl, J., Chan, K., Ahmed, R., Tripković, V. \& Björketun, M. E. pH in atomic scale simulations of electrochemical interfaces. Phys. Chem. Chem. Phys. 15, 10321-10325 (2013).

65. Drexler, C. I. et al. Counter cations affect transport in aqueous hydroxide solutions with ion specificity. J. Am. Chem. Soc. 141, 6930-6936 (2019)

66. Marx, D., Tuckerman, M. E., Hutter, J. \& Parrinello, M. The nature of the hydrated excess proton in water. Nature 397, 601-604 (1999).

67. Ledezma-Yanez, I. et al. Interfacial water reorganization as a pH-dependent descriptor of the hydrogen evolution rate on platinum electrodes. Nat. Energy 2, 17031 (2017).

68. Kresse, G. \& Furthmüller, J. Efficient iterative schemes for ab initio totalenergy calculations using a plane-wave basis set. Phys. Rev. B Condens. Matter Mater. Phys. 54, 11169 (1996).

69. Dudarev, S. L., Botton, G. A., Savrasov, S. Y., Humphreys, C. J. \& Sutton, A. P. Electron-energy-loss spectra and the structural stability of nickel oxide: an LSDA+U study. Phys. Rev. B 57, 1505-1509 (1998).

70. Blöchl, P. E. Projector augmented-wave method. Phys. Rev. B Condens. Matter Mater. Phys. 50, 17953 (1994).
71. Kresse, G. \& Joubert, D. From ultrasoft pseudopotentials to the projector augmented-wave method. Phys. Rev. B Condens. Matter Mater. Phys. 59, 1758 (1999).

72. Blöchl, P. E., Jepsen, O. \& Andersen, O. K. Improved tetrahedron method for Brillouin-zone integrations. Phys. Rev. B 49, 16223-16233 (1994).

73. Grimme, S., Antony, J., Ehrlich, S. \& Krieg, H. A consistent and accurate ab initio parametrization of density functional dispersion correction (DFT-D) for the 94 elements H-Pu. J. Chem. Phys. 132, 154104 (2010).

74. Grimme, S., Ehrlich, S. \& Goerigk, L. Effect of the damping function in dispersion corrected density functional theory. J. Comput. Chem. 32, 1456-1465 (2011)

75. Mathew, K., Sundararaman, R., Letchworth-Weaver, K., Arias, T. A. \& Hennig, R. G. Implicit solvation model for density-functional study of nanocrystal surfaces and reaction pathways. J. Chem. Phys. 140, 84106 (2014)

\section{Acknowledgements}

We thank the Knut and Alice Wallenberg Foundation, the Swedish Research Council, and the Åforsk Foundation, and StandUp for Energy for financial support. We also thank Kjell Jansson at Stockholm University for assistance with SEM-EDS measurements. We also greatly thank Wolfgang Caliebe and the staff at the P-64 beamline at Petra III (DESY, Hamburg), with financial support from the Bundesministerium für Bildung und Forschung (BMBF) project no. 05K19PXA. We thank Urs Vogelsang of the SuperXAS beamline at Swiss Light Source (PSI), and Juan Herranz Salaner at PSI for support. Computational resources were provided by the Swedish National Infrastructure for Computing (SNIC) at the National Supercomputer Center (NSC).

\section{Author contributions}

M.G. carried out the data analysis, wrote the manuscript and prepared the figures for the experimental data results. J.H.S. carried out the density functional theory calculations and prepared the figures for the DFT data results, and wrote the text for the DFT section. O.D.M. contributed specifically to data interpretation, overall experimental design, and electrochemical characterization. M.G., O.D.M., S.K., H.Y.W., M. Börner, and M.S. all contributed equally to XAS data collection, and S.K. and H.Y.W. contributed especially to XAS data interpretation. A.K., V.M., O.V.S., M.N., and M. Bauer contributed to XAS data collection and overall experimental design/setup, J.D. and A.U. assisted with elemental analysis, and A.N. provided hands-on supervision and support throughout the project. The manuscript content has been commented and discussed by all co-authors.

\section{Funding}

Open Access funding provided by Uppsala University.

\section{Competing interests}

The authors declare no competing interests.

\section{Additional information}

Supplementary information is available for this paper at https://doi.org/10.1038/s41467 020-19729-2.

Correspondence and requests for materials should be addressed to M.Gör. or O.D.-M

Peer review information Nature Communications thanks Yanbo Li, Björn Wickman and the other anonymous reviewers for their contribution to the peer review of this work. Peer reviewer reports are available.

Reprints and permission information is available at http://www.nature.com/reprints

Publisher's note Springer Nature remains neutral with regard to jurisdictional claims in published maps and institutional affiliations.

Open Access This article is licensed under a Creative Commons Attribution 4.0 International License, which permits use, sharing, adaptation, distribution and reproduction in any medium or format, as long as you give appropriate credit to the original author(s) and the source, provide a link to the Creative Commons license, and indicate if changes were made. The images or other third party material in this article are included in the article's Creative Commons license, unless indicated otherwise in a credit line to the material. If material is not included in the article's Creative Commons license and your intended use is not permitted by statutory regulation or exceeds the permitted use, you will need to obtain permission directly from the copyright holder. To view a copy of this license, visit http://creativecommons.org/ licenses/by/4.0/.

(C) The Author(s) 2020 